\title{
Absolute Salinity, "Density Salinity" and the Reference-Composition Salinity Scale: present and future use in the seawater standard TEOS-10
}

\author{
D. G. Wright ${ }^{1, \dagger}$, R. Pawlowicz ${ }^{2}$, T. J. McDougall ${ }^{3}$, R. Feistel ${ }^{4}$, and G. M. Marion ${ }^{5}$ \\ ${ }^{1}$ Bedford Institute of Oceanography, Dartmouth, NS, B2Y 4A2, Canada \\ ${ }^{2}$ Department of Earth and Ocean Sciences, University of British Columbia, Vancouver, BC V6T 1Z4, Canada \\ ${ }^{3}$ CSIRO Marine and Atmospheric Research, G.P.O. Box 1538, Hobart, TAS 7001, Australia \\ ${ }^{4}$ Leibniz-Institut für Ostseeforschung, Seestraße 15, 18119 Warnemünde, Germany \\ ${ }^{5}$ Desert Research Institute, Reno, NV, USA \\ $\dagger$ deceased
}

Received: 30 May 2010 - Published in Ocean Sci. Discuss.: 31 August 2010

Revised: 2 December 2010 - Accepted: 18 December 2010 - Published: 6 January 2011

\begin{abstract}
Salinity plays a key role in the determination of the thermodynamic properties of seawater and the new TEOS- $10^{1}$ standard provides a consistent and effective approach to dealing with relationships between salinity and these thermodynamic properties. However, there are a number of practical issues that arise in the application of TEOS10 , both in terms of accuracy and scope, including its use in the reduction of field data and in numerical models.

First, in the TEOS-10 formulation for IAPSO Standard Seawater, the Gibbs function takes the Reference Salinity as its salinity argument, denoted $S_{\mathrm{R}}$, which provides a measure of the mass fraction of dissolved material in solution based on the Reference Composition approximation for Standard Seawater. We discuss uncertainties in both the Reference Composition and the Reference-Composition Salinity Scale on which Reference Salinity is reported. The Reference Composition provides a much-needed fixed benchmark but modified reference states will inevitably be required to improve the representation of Standard Seawater for some studies. However, the Reference-Composition Salinity Scale should remain unaltered to provide a stable representation of salinity for use with the TEOS-10 Gibbs function and in climate change detection studies.

Second, when composition anomalies are present in seawater, no single salinity variable can fully represent the in-
\end{abstract}

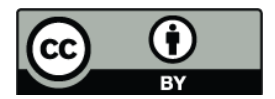

Correspondence to: R. Pawlowicz (rpawlowicz@eos.ubc.ca)

${ }^{1}$ TEOS-10: international Thermodynamic Equation of Seawater 2010, www.teos-10.org. fluence of dissolved material on the thermodynamic properties of seawater. We consider three distinct representations of salinity that have been used in previous studies and discuss the connections and distinctions between them. One of these variables provides the most accurate representation of density possible as well as improvements over Reference Salinity for the determination of other thermodynamic properties. It is referred to as "Density Salinity" and is represented by the symbol $S_{\mathrm{A}}^{\text {dens }}$; it stands out as the most appropriate representation of salinity for use in dynamical physical oceanography. The other two salinity variables provide alternative measures of the mass fraction of dissolved material in seawater. "Solution Salinity", denoted $S_{\mathrm{A}}^{\text {soln }}$, is the most obvious extension of Reference Salinity to allow for composition anomalies; it provides a direct estimate of the mass fraction of dissolved material in solution. "Added-Mass Salinity", denoted $S_{\mathrm{A}}^{\text {add }}$, is motivated by a method used to report laboratory experiments; it represents the component of dissolved material added to Standard Seawater in terms of the mass of material before it enters solution. We also discuss a constructed conservative variable referred to as "Preformed Salinity", denoted $S_{*}$, which will be useful in process-oriented numerical modelling studies.

Finally, a conceptual framework for the incorporation of composition anomalies in numerical models is presented that builds from studies in which composition anomalies are simply ignored up to studies in which the influences of composition anomalies are accounted for using the results of biogeochemical models. 


\section{Introduction}

The relationships between the chemical composition, conductivity, salinity, and thermodynamic properties of IAPSO Standard Seawater, modified only by the addition and removal of pure water through dilution and evaporation (hereafter denoted SSW), are now defined to the best available precision by a linked series of standards. Millero et al. (2008a) (hereafter referred to as MFWM) define a fixed Reference Composition (RC) as an estimate of the relative mole fractions of the components of dissolved material in SSW, and link this to the conductivity/salinity relationship defined by the Practical Salinity Scale 1978 or PSS-78 (UNESCO, 1981). Among other benefits, salinities can now be referenced on an absolute or mass fraction scale, directly related to the dissolved material within seawater. Thermodynamic properties, including density, are consistently linked to salinity by a thermodynamic equation of state for seawater (TEOS-10) represented in terms of a Gibbs function formulation, which itself is based on a comprehensive evaluation of all relevant data (Feistel, 2008, 2010; Feistel et al., 2010a, b; IOC et al., 2010).

However, as discussed here, our direct knowledge of the true chemical composition of SSW has an uncertainty which is equivalent to a mass fraction salinity uncertainty of order $0.05 \mathrm{~g} \mathrm{~kg}^{-1}$, whereas modern conductivity-based measurement techniques can routinely resolve spatial variations of as little as $0.002 \mathrm{~g} \mathrm{~kg}^{-1}$ in salinity. Work done subsequent to MFWM already suggests the presence of small systematic deviations in the relative composition of SSW compared to the RC. Further, even leaving aside the issue of the exact composition of SSW, the composition of real seawater from different parts of the world oceans is known to differ slightly from the composition of SSW, which is derived from North Atlantic surface water. These composition anomalies are in fact the single largest source of errors in estimates of the thermodynamic properties of real seawater when TEOS10 equations are used under the assumption that composition anomalies are negligible. We are thus led to pose two questions: first, is the fixed composition model and the associated absolute salinity scale an appropriate enduring approach, and second, can we adapt the TEOS-10 formulation to incorporate additional information about these composition variations.

Regarding the Reference Composition defined by MFWM, it is clear that this can serve as a useful benchmark even though the connection with SSW is limited by both data uncertainties and the variability in SSW itself. Further, it is obvious that changes in the definition of the RC would have the potential to cause confusion in the future. Thus, although refinements of the RC will inevitably be required for particular applications (e.g., Pawlowicz, 2010; Pawlowicz et al., 2010), we argue that the set of molar ratios defining the RC should be established as a fixed benchmark.
The use of a fixed absolute salinity scale and the SSW Gibbs function formulation to characterize arbitrary seawaters, affected by biogeochemical processes in the ocean, is less obvious. Although the full ramifications of this choice are not yet definitively known, recent investigations (Millero et al., 2008a, b, 2009; McDougall et al., 2009; Pawlowicz, 2010; Pawlowicz et al., 2010; Feistel et al., 2010a, b; Seitz et al., 2008, 2010a, b) have yielded estimates of the magnitude of the resulting errors in different circumstances, as well as some details of the operational issues that arise. Here we discuss our present understanding of these issues.

These recent investigations have also highlighted some conceptual difficulties that are not present when discussion is limited to SSW. The term "Absolute Salinity" has been defined for Reference-Composition Seawater (RCSW) and SSW in MFWM and used as a measure of dissolved material in seawater in previous publications (McDougall et al., 2009; Feistel et al., 2010a). In this context, the term "absolute" is taken as implying a true mass fraction measure. This is in contrast to the traditional Practical Salinity, which is defined as a function of conductivity ratio at reference conditions with the function chosen to give a result proportional to Chlorinity, and with the proportionality constant chosen for consistency with past practice, rather than a best estimate of the mass fraction of dissolved material. However, the meaning of "Absolute Salinity" has not yet been precisely defined for seawaters with composition anomalies. Here we consider seawaters with composition anomalies and show that in this case the absolute salinity can be characterized in a number of different ways. A family of salinity variables is defined and a consistent notation introduced to facilitate the discussion of their features and interrelationships.

The introduction of new salinity variables that allow for the presence of composition anomalies will increase both the opportunities and the complications involved in quantifying the ocean circulation. It has been common practice to ignore composition anomalies in numerical models and assume perfect conservation of dissolved material to represent the evolution of salinity. The result has then been identified with Practical Salinity to represent the effects of dissolved material on density. Similar approximations have been used in observational studies (Lewis, 1981), but this is no longer the most accurate approximation available. One of the new variables, the "Density Salinity", is proposed as an observational parameter which should provide a measure of absolute salinity with the most general utility for oceanographic research, to be implied by the term "Absolute Salinity". This is because it allows for the most accurate calculations of density. For numerical modelling of ocean circulation, the salinity variable referred to as "Preformed Salinity" will also be very useful since it corresponds to a measure of seawater with the influences of biogeochemical processes removed. A hierarchy of possible numerical approaches is outlined that allow for the effects of composition anomalies added to Preformed Salinity. Thus for numerical modelling purposes, Density Salinity 
is determined as the sum of Preformed Salinity and an appropriately defined anomaly.

In Sect. 2, we briefly review the set of salinity variables that have been used in recent studies and in Sect. 3 we consider issues associated with SSW in the absence of composition anomalies. The accuracy of the Reference-Composition Salinity Scale is reviewed and an argument is presented that future updates of the Reference-Composition Salinity Scale should be avoided in order to provide the required stability of the measurement scale. In Sect. 4 we consider various representations of the dissolved material in seawater that includes composition anomalies. Several representations of the mass fraction of dissolved material in seawater, including the Density Salinity, are defined and approximations used to estimate them are considered. Additional considerations regarding the validity of using Density Salinity as an argument of the Gibbs function are also discussed. A framework for the consideration of the effects of composition anomalies in numerical models is proposed in Sect. 5. Section 6 provides a summary and conclusions.

\section{A family of salinity variables}

In this article, we refer to seven measures of salinity: Chlorinity $\mathrm{Cl}$, Practical Salinity $S_{\mathrm{P}}$, Reference Salinity $S_{\mathrm{R}}$, Density Salinity $S_{\mathrm{A}}^{\text {dens }}$, Solution Salinity $S_{\mathrm{A}}^{\text {soln }}$, Added-Mass Salinity $S_{\mathrm{A}}^{\text {add }}$, and Preformed Salinity $S_{*}$. Each of these salinity variables have been discussed in previous publications (Millero et al., 2008a, b, 2009; McDougall et al., 2009; IOC et al., 2010; Pawlowicz, 2010; Pawlowicz et al., 2010), although not necessarily in a consistent or explicit manner. Their definitions will be formalized here. An explanation of the notation used and a figure to illustrate the relations between the various measures of salinity and density is provided in Appendix A.

Chlorinity is the oldest of the salinity measures considered and is still a corner-stone in the study of dissolved material in seawater. Based on the principle of constant relative proportions it provides a measure of the total amount of dissolved material in seawater in terms of the concentration of halides. Practical Salinity has been the internationally accepted standard for the representation of ocean salinity for the past 3 decades; for SSW it is basically a scaled version of Chlorinity estimated via the measurement of conductivity. Reference Salinity is defined by MFWM to provide a measure of the mass fraction of dissolved material in SSW, and incorporates the result of a century of study into the true composition of seawater. The most practical way to estimate Reference Salinity over the Neptunian range of conditions is to determine Practical Salinity and multiply by the fixed scale factor $(35.16504 / 35) \mathrm{g} \mathrm{kg}^{-1}$. We note however that Reference Salinity provides the best estimate of the mass fraction of solute in a seawater sample only if it has the composition of SSW. The last 4 Salinity Variables have been introduced to more accurately deal with seawater that includes composition anomalies with respect to SSW and are discussed in Sect. 4. Preformed Salinity $S_{*}$ is constructed to be as conservative as possible; it is designed to be insensitive to biogeochemical processes that affect the other types of salinity to varying degrees. For SSW, five of the salinity variables are equal, the exceptions being Chlorinity and Practical Salinity.

As discussed by MFWM and others before them, if the relative proportions of dissolved material in seawater can be assumed constant, then Chlorinity provides a suitable proxy measure of dissolved material in seawater. It is defined as 0.3285234 times the ratio of the mass of pure silver $(\mathrm{g}) \mathrm{re}-$ quired to precipitate all dissolved halides (chloride, bromide and iodide) in seawater to the mass of seawater ( $\mathrm{kg}$ ). Problems with this measure of salinity are that Chlorinity must be measured by a skilled technician using a precise silver standard, the process is time consuming, and Chlorinity cannot be measured in situ, but only on collected water samples. Also, the approach assumes a fixed (or at least precisely known) composition of dissolved material in order to convert from Chlorinity to a dissolved mass fraction. Finally, the reproducibility of the silver standard and its traceability to a reliable SI reference is unclear.

Practical Salinity $S_{\mathrm{P}}$ was introduced 30 years ago as a replacement for Chlorinity that addresses the first set of issues, but does not properly account for composition anomalies or allow traceability to the SI (Lewis, 1981). Practical Salinity is relatively easy to measure using now standard equipment, measurements are more precise and less time consuming than measurements of Chlorinity and accurate measurements can even be made in situ. The success of the method relies on the fact that for a fixed composition at specified temperature and pressure, the conductivity is related in a one-to-one manner to the mass ratio of dissolved material in seawater and the conductivity ratio relative to a standard can be precisely measured using robust techniques. Further, reliable standards are routinely available in numbered batches from the Standard Seawater Service (Bacon et al., 2007). In practice, a polynomial relation was empirically determined to calculate Chlorinity $\mathrm{Cl}$ from a measured conductivity ratio and the resulting estimate of Chlorinity was converted to Practical Salinity using $S_{\mathrm{P}}=1.80655 \mathrm{Cl} /\left(\mathrm{g} \mathrm{kg}^{-1}\right)$, a choice that was made to maintain numerical continuity with historical salinity estimates at $C l=(35 / 1.80655) \mathrm{g} \mathrm{kg}^{-1}$. The strict definition of Practical Salinity requires that measurements be made at a pressure of $P=101325 \mathrm{~Pa}$ and $t=15^{\circ} \mathrm{C}$ on the IPTS-68 temperature scale $\left(t=14.996^{\circ} \mathrm{C}\right.$ on the ITS- $90^{3}$ scale), but algorithms are available to convert from conductivity measurements at other pressure and temperature values so this is not a serious restriction as long as any composition anomalies present do not corrupt these conversion relations (Feistel and Weinreben, 2008). This is unlikely to be a serious concern

\footnotetext{
2 IPTS-68: International Practical Temperature Scale 1968

${ }^{3}$ ITS-90: International Temperature Scale 1990
} 
in the open ocean given that Pawlowicz (2010) estimates the maximum error in the temperature correction to be of order $0.0004 \mathrm{~g} \mathrm{~kg}^{-1}$ when converting from $1{ }^{\circ} \mathrm{C}$ to $25^{\circ} \mathrm{C}$ for North Pacific Intermediate Water where composition anomalies are near maximum.

MFWM list several reasons that a revised estimate of salinity is now desirable. Five of these are: (1) to introduce a chemical composition model for SSW which can be used in defining the Gibbs function for seawater at low salinities; (2) to adjust the numerical value of the standard measure of salinity to be as close as possible, given measurement uncertainties, to the true mass fraction of dissolved material in SSW (i.e., its absolute salinity); (3) to formally allow for arbitrarily large or small values of salinity, (4) to overcome the $T-P$ limitations of PSS-78, and (5) to officially allow mass fraction units for salinity and make oceanographic papers more readable for the wider scientific community. To achieve these goals, they define a stoichiometric composition model for SSW (the Reference Composition or RC), determine a "best estimate" of the mass fraction of dissolved material corresponding to this model at a Practical Salinity of 35 , and specify an algorithm to determine a consistent estimate of the mass fraction of dissolved material in a sample of arbitrary salinity with the RC. The resulting measure of salinity is referred to as the Reference-Composition Salinity $S_{\mathrm{R}}$ (or simply Reference Salinity) and the scale on which the Reference Salinity is measured is referred to as the Reference-Composition Salinity Scale (RCSS). By using this approach, the Reference Salinity provides an estimate of the mass fraction of dissolved material in any seawater sample by approximating it with seawater that has the Reference Composition defined by MFWM.

The use of a single absolute salinity variable to represent the material dissolved in a seawater sample is most appropriate for SSW because it has a nearly fixed relative composition. In fact, IAPSO Standard Seawater can be considered as a physical realization of the Reference-Composition Seawater construct. Nevertheless, it should be noted that the composition of SSW from different batch numbers must vary as a consequence of its natural origin, and the exact magnitude of these changes is presently unknown. Even as a conductivity standard there are indications from the intercomparison of field measurements that batch-specific offsets of up to about 0.003 in Practical Salinity occur (Kawano et al., 2006), although the reasons for this have been disputed (Bacon et al., 2007). Seawaters of arbitrary origin may include much larger composition anomalies that will further distinguish them from RCSW. Since these anomalies are of scientific interest it is appropriate to consider them separately.

For a seawater sample of arbitrary composition, a single measure of absolute salinity is too simple to fully describe its properties. This point is most obvious if one considers the dissolution in seawater of a substance that affects density and other properties but does not affect conductivity (silicic acid and sugar provide examples for which this is a reason- able approximation). In such a case, the Practical Salinity $S_{\mathrm{P}}$ and the Reference Salinity $S_{\mathrm{R}}$, both of which are functions of the conductivity of seawater, each remain almost unchanged even for significant changes to the mass fraction of solute present in the solution. Similarly, Chlorinity is almost unaffected by the addition of typical composition anomalies (real seawater anomalies do not normally include halides but they do slightly modify the mass of solution). Thus, none of these quantities provide a measure of the change in the mass fraction of dissolved material in seawater that allows for general composition anomalies.

In fact, there is still no practical means to actually determine the mass fraction of dissolved material in water for the general case. Hence a precise and easily obtained measure of the amount of dissolved material in seawater is required as an extension of Reference Salinity to allow for composition anomalies. Any extension must agree precisely with the Reference Salinity when the dissolved material has the composition assigned to Standard Seawater. In addition, it is desirable to introduce a measure of salinity that is traceable to the SI (Seitz et al., 2008, 2010a, b; IOC et al., 2010) which is not achieved by the introduction of Reference Salinity (Seitz, 2010b). We shall argue that the introduction of "Density Salinity" $S_{\mathrm{A}}^{\text {dens }}$ addresses both of these issues.

It should be noted that MFWM interchangeably used the words "Absolute Salinity" and the symbol $S_{\mathrm{A}}$ for what we now recognize as two different absolute salinity measures, Solution Salinity and Density Salinity. For most of that paper MFWM discuss SSW for which these measures of salinity are equivalent to within measurement uncertainties, but with an implication of Solution Salinity. However, in Sect. 7 of MFWM they consider the influence of composition anomalies and they use the words Absolute Salinity and the symbol $S_{\mathrm{A}}$ for what we now call Density Salinity with the symbol $S_{\mathrm{A}}^{\text {dens }}$.

We now consider uncertainties associated with the definition of the RCSS and the representation of the salinity of SSW. We discuss the effects of composition anomalies in Sect. 4.

\section{The Reference-Composition Salinity Scale and the salinity of SSW}

The Reference Composition was introduced by MFWM for two primary purposes: to establish a benchmark representation of the composition of SSW, and to determine a "best estimate" of the mass fraction of dissolved material in SSW, and was then used to determine a scale, the ReferenceComposition Salinity Scale. Since all of our salinity estimates except Practical Salinity will be expressed on the RCSS, we first review the definition of this scale and the uncertainties associated with its definition. In this section we deal with the RCSS in the context of SSW. That is, we discuss how accurately the RCSS represents the true absolute salinity 
of a water sample whose composition precisely matches the SSW that was analyzed in the 1970s, when most of the conductivity and density measurements underlying both EOS$80^{4}$ and TEOS-10 were made. Since the different measures of absolute salinity are defined to be equal for SSW it is appropriate to use the symbol $S_{\mathrm{A}}$ without a superscript in this section.

\subsection{Uncertainties in the Reference-Composition Salinity Scale}

The Reference Composition includes all important components of seawater having mass fractions greater than about $1 \mathrm{mg} \mathrm{kg}^{-1}$ in seawater with a Practical Salinity of 35 that can significantly affect either the conductivity or the density. All mass fractions were defined using the best available information for concentrations and molar masses in 2008, and the $\mathrm{RC}$ was carefully adjusted to be in charge balance. The uncertainty in the molar masses alone gives rise to a mass fraction salinity uncertainty of about $1 \mathrm{mg} \mathrm{kg}^{-1}$ (Millero et al., 2008a), but there are larger sources of uncertainty.

The most significant ions present in seawater but not included in the $\mathrm{RC}$ are $\mathrm{Li}^{+}\left(\sim 0.18 \mathrm{mg} \mathrm{kg}^{-1}\right)$ and $\mathrm{Rb}^{+}$ $\left(\sim 0.12 \mathrm{mg} \mathrm{kg}^{-1}\right)$. Dissolved gases $\mathrm{N}_{2}\left(\sim 16 \mathrm{mg} \mathrm{kg}^{-1}\right)$ and $\mathrm{O}_{2}$ (up to about $8 \mathrm{~m} \mathrm{~kg}^{-1}$ ) are not included since they are highly variable and neither have a significant effect on density or on conductivity. In addition, $\mathrm{N}_{2}$ remains within a few percent of saturation for the measured temperature in almost all laboratory and in-situ conditions. However, the dissolved gas $\mathrm{CO}_{2}\left(\sim 0.7 \mathrm{mg} \mathrm{kg}^{-1}\right)$ and the ion $\mathrm{OH}^{-}\left(\sim 0.08 \mathrm{mg} \mathrm{kg}^{-1}\right)$ are included in the $\mathrm{RC}$ in spite of their small concentrations because of their important role in the equilibrium dynamics of the carbonate system. Changes in $\mathrm{OH}^{-}$concentration that are commonly expressed in terms of $\mathrm{pH}$ involve conversion of $\mathrm{CO}_{2}$ to and from other ionic forms and affect conductivity and density. The RC concentrations of the carbonate system components were determined by taking the known total alkalinity, assuming equilibrium with the levels of $\mathrm{CO}_{2}$ gas in the atmosphere in 1976, and then using known mathematical relationships for the equilibrium chemistry. Concentrations of the major nutrients $\mathrm{Si}(\mathrm{OH})_{4}, \mathrm{NO}_{3}^{-}$, and $\mathrm{PO}_{4}^{3-}$ are assumed to be negligible in SSW. Dissolved Organic Matter (DOM) is typically present at concentrations of $0.5-2 \mathrm{mg} \mathrm{kg}^{-1}$ in the ocean, but its composition in seawater is complex and poorly known. Although its concentration in SSW is unknown it is likely to be smaller because of the filtration used in the manufacturing procedure. It is not included in the RC.

The Reference-Composition Salinity Scale (RCSS) is defined implicitly in MFWM by an algorithm that is used to specify the Reference Salinity $S_{\mathrm{R}}$. The Reference Salinity is defined to provide an estimate of the (mass fraction) absolute salinity of seawater with the RC. It is given

\footnotetext{
${ }^{4}$ EOS-80: International equation of state of seawater 1980 (Fofonoff and Millard, 1983)
}

in terms of two end members, pure water defined as Vienna Standard Mean Ocean Water (VSMOW; IAPWS, 2001) and KCl-normalized Reference-Composition Seawater (RCSW) which is seawater with the Reference Composition at $t=25^{\circ} \mathrm{C}, P=101325 \mathrm{~Pa}$ that has been adjusted to a Practical Salinity $S_{\mathrm{P}}$ of 35 (exactly) through the addition or removal of VSMOW. The Reference Salinities of VSMOW and KCl-normalized RCSW are defined to be exactly $0 \mathrm{~g} \mathrm{~kg}^{-1}$ and $35.16504 \mathrm{~g} \mathrm{~kg}^{-1}$, respectively. The Reference Salinity of an arbitrary sample of RCSW is then defined by assuming conservation of dissolved material during the addition or removal of pure water to the sample. If a sample with mass $m_{1}$ requires the addition or removal of a mass $m_{2}$ ( $>0$ for addition and $<0$ for removal) to bring its Practical Salinity to $S_{\mathrm{P}}=35$, then its Reference Salinity is $\left(1+m_{2} / m_{1}\right) \times 35.16504 \mathrm{~g} \mathrm{~kg}^{-1}$. Reference Salinity is not modified by changes in temperature or pressure that are made without mass exchange. Note that in reality, there are small changes in the relative composition of a seawater sample associated with changes in temperature, pressure and concentration. This is because equilibrium chemistry relationships between some of the constituents depend on these factors. Consequently, Reference Salinity is perhaps best thought of as a potential mass fraction salinity that is obtained under the particular reference conditions discussed above.

As noted by MFWM, the value of the Absolute Salinity $S_{\mathrm{A}}$ of RCSW can be related to the atomic weights of the constituents and the Chlorinity of the sample by:

$S_{\mathrm{A}}=\left[0.3285234 \times\left(A_{\mathrm{Ag}} /\langle A\rangle\right) \times\left(X_{C l}+X_{\mathrm{Br}}\right)\right]^{-1} C l$,

where $X_{C l}$ and $X_{\mathrm{Br}}$ are the mole fractions of chlorine and bromine in the sea salt, $A_{\mathrm{Ag}}$ is the atomic weight of silver, $\langle A\rangle$ is the mole-weighted mean atomic weight of solute with the Reference Composition and $\mathrm{Cl}$ is the Chlorinity of the sample of RCSW. The mole fractions of dissolved material in RCSW are precisely defined and Eq. (1) is exact for this composition. Thus, for specified Chlorinity the only source of uncertainty in the determination of $S_{\mathrm{A}}$ from Eq. (1) is the uncertainty associated with the atomic weights. For a typical sample with Practical Salinity near 35 (Chlorinity near $19.374 \mathrm{~g} \mathrm{~kg}^{-1}$ ) the resulting uncertainty in $S_{\mathrm{A}}$ is only about $0.001 \mathrm{~g} \mathrm{~kg}^{-1}$ (Millero et al., 2008a).

However, estimates of salinity rely on conductivity measures, so MFWM rewrite Eq. (1) as

$S_{\mathrm{A}}=u_{\mathrm{PS}} S_{\mathrm{P}}$,

where the RCSS scale factor $u_{\mathrm{PS}}$ is defined by

$u_{\mathrm{PS}}=\left[0.3285234 \times \operatorname{Son} C l \times\left(A_{\mathrm{Ag}} /\langle A\rangle\right) \times\left(X_{C l}+X_{\mathrm{Br}}\right)\right]^{-1}$,

with the quantity Son $C l$ defined as the ratio of Practical Salinity to Chlorinity for RCSW. MFWM note that the value of Son $\mathrm{Cl}$ is unknown for RCSW because of practical difficulties associated with the preparation of a solution of RC in the laboratory (Kester et al., 1967; Millero and Lepple, 1973; 
Millero, 2010), and approximate Son $C l$ by the value 1.80655 $\left(\mathrm{g} \mathrm{kg}^{-1}\right)^{-1}$, which is the value appropriate to SSW (Dauphinee, 1981; Culkin and Smith, 1981). This choice is supported by the fact that the RC was defined as a "best approximation" to the composition of SSW. However, there are uncertainties associated with this value. In particular, any modification of the estimated composition of SSW would imply a difference between its composition and the fixed composition of RCSW, and this could imply a change in the best estimate of SonCl that should be used for the latter in Eq. (1), and thus a deviation of the ratio $S_{\mathrm{A}} / S_{\mathrm{R}}$ from unity for RCSW. The uncertainty associated with $\mathrm{SonCl}$ is by far the largest source of uncertainty associated with the determination of the Absolute Salinity of RCSW using Eqs. (2) and (3).

We note however that our interest in Eqs. (1-3) is based on the fact that they provide a means to estimate the absolute salinity of SSW rather than a specific interest in the absolute salinity of the theoretical water type referred to as RCSW. Consequently, it is of interest to consider the true uncertainties associated with the use of these equations for this purpose. To investigate this issue, we take a slightly different approach to that presented by MFWM.

Consider a sample of SSW that was used in the determination of PSS-78 and assume that its Practical Salinity has been precisely determined. Since the relation $S_{\mathrm{P}}=1.80655 \mathrm{Cl} /\left(\mathrm{g} \mathrm{kg}^{-1}\right)$ was used as a definition to convert between Chlorinity measurements and Practical Salinity for this particular vintage of SSW, we can use this relation as an identity here. Thus, given the Practical Salinity of our SSW sample, we know the value of its Chlorinity. Using Eq. (1), we now determine the Absolute Salinity of RCSW that has the same value of Chlorinity and we use this value as an estimate of the absolute salinity of our SSW sample.

There are subtle but important points to note about the modified interpretation given in the previous paragraph. First, the resulting value of Absolute Salinity is recognized as an estimate of the absolute salinity of the SSW sample rather than that of the ideal RCSW sample used in the estimation procedure. Second, the estimate of the absolute salinity of the SSW sample with measured Practical Salinity is given by Eqs. (2) and (3) and is thus exactly the same as the estimate of the absolute salinity of the RCSW sample with the same Practical Salinity. Third, the use of Son $C l=1.80655$ $\left(\mathrm{g} \mathrm{kg}^{-1}\right)^{-1}$ for RCSW has been completely eliminated. Consequently, neglecting the small uncertainties associated with the atomic weight estimates, determination of the uncertainty associated with the use of $S_{\mathrm{R}}$ as a measure of the absolute salinity of SSW is reduced to consideration of the accuracy of the RC as a representation of SSW.

We emphasize that use of Eqs. (2) and (3) to estimate the absolute salinity of a sample of RCSW involves uncertainties associated with the use of the value of Son $C l$ for SSW but it does not involve any uncertainties associated with the mole fractions since these are precisely defined for RCSW. On the other hand, use of Eqs. (2) and (3) to directly estimate the absolute salinity of a sample of SSW as described above involves uncertainties associated with the use of RCSW as a model for SSW, but it does not involve any uncertainties associated with the value of SonCl since this value is precisely known for the SSW samples of interest. Since our true interest is in estimating the absolute salinity of SSW, the use of Eqs. (2) and (3) to directly estimate the absolute salinity of a sample of SSW is preferred here and we continue to consider the uncertainties associated with using RCSW as a model for SSW.

Even at the time that the RC was defined it was clear that uncertainty in the true composition of SSW was larger than the scientific requirements for precision in a salinity measure, which are about $0.002 \mathrm{~g} \mathrm{~kg}^{-1}$. Recently, Seitz (2010a and personal communication 2010) have estimated the sulfate $\left(\mathrm{SO}_{4}^{2-}\right)$ mass fraction of a sample of $\mathrm{KCl}$-normalized SSW to be $2.702 \pm 0.022 \mathrm{~g} \mathrm{~kg}^{-1}$. This range of values overlaps with the Reference Composition value of $2.71235 \mathrm{~g} \mathrm{~kg}^{-1}$ so it does not suggest any need to revise the RC at this time. However, it also includes a lower bound of $2.68 \mathrm{~g} \mathrm{~kg}^{-1}$ which cannot currently be ruled out as a representation of the properties of SSW. If the estimated sulfate mass fraction in SSW were reduced from $2.71235 \mathrm{~g} \mathrm{~kg}^{-1}$ to $2.68 \mathrm{~g} \mathrm{~kg}^{-1}$ (a reduction of $337 \mu \mathrm{mol} \mathrm{kg}{ }^{-1}$ ), then upon using the approach of MFWM in which the sodium $\left(\mathrm{Na}^{+}\right)$concentration is adjusted to achieve charge balance, the estimated absolute salinity of the resulting modified RCSW would be reduced from $35.16504 \mathrm{~g} \mathrm{~kg}^{-1}$ to $35.11114 \mathrm{~g} \mathrm{~kg}^{-1}$. This suggests the possibility that a future change in the estimated absolute salinity of SSW with $S_{\mathrm{P}}=35$ could be as large as $0.054 \mathrm{~g} \mathrm{~kg}^{-1}$, more than an order of magnitude larger than the precision of Practical Salinity measurements and one third of the difference between 35.16504 and 35 , i.e., the difference between $S_{\mathrm{R}} /\left(\mathrm{g} \mathrm{kg}^{-1}\right)$ and $S_{\mathrm{P}}$ for KClnormalized RCSW.

There are smaller uncertainties in the composition of SSW and its absolute salinity associated with uncertainties in carbonate chemistry. Uncertainties associated with the equilibrium constants involved result in uncertainties in the absolute salinity of SSW of order $0.0002 \mathrm{~g} \mathrm{~kg}^{-1}$ or less. Similarly, the estimated amount of boric acid in SSW has recently been revised upwards by $0.001 \mathrm{~g} \mathrm{~kg}^{-1}$ (Lee et al., 2010). A potentially larger effect arises from uncertainties about the amount of Dissolved Inorganic Carbon (DIC) present in the 1970s SSW. For example, for a KCl-normalized sample, the SSW76 composition used as a representation of SSW by Pawlowicz (2010) has a DIC value that is $117 \mu \mathrm{mol} \mathrm{kg} \mathrm{kg}^{-1}$ higher than that associated with the RC. Using Eq. (51) from Pawlowicz et al. (2010), we find that this difference alters the mass fraction absolute salinity by about $0.0055 \mathrm{~g} \mathrm{~kg}^{-1}$. This change is almost an order of magnitude smaller than uncertainties associated with other aspects of the composition (e.g., sulfate), but still larger than the uncertainties associated with Practical Salinity measurements. 
The above discussion deals with the accuracy of the RCSS for the determination of the absolute salinity of SSW. That is, it deals with the issue of how accurately the Reference Salinity, determined from conductivity, represents the mass fraction of dissolved material in solution for the ideal case of a sample of 1970s SSW. We have seen that the inaccuracies may be as large as $0.05 \mathrm{~g} \mathrm{~kg}^{-1}$ which is substantially larger than the contributions to the mass fraction of dissolved material from composition anomalies that we consider in some detail in Sect. 4. However, these offsets will affect all salinity values proportionately and are accounted for in the definition of the Gibbs function for SSW, whereas the composition anomalies discussed in Sect. 4 vary spatially and directly influence horizontal pressure gradients. In the next section, we consider whether the uncertainties in the absolute salinities of SSW and RCSW might result in a need to update the RCSS in the future.

\subsection{Will the RCSS need to be updated in the future?}

The above discussion emphasizes the uncertainty in the use of the Reference Salinity to estimate the mass fraction of dissolved material in 1970s SSW. It motivates us to ask what should happen if an improved estimate of the composition of this vintage of SSW is determined in the future. At first, it would seem natural to update the Reference Composition and hence the estimate of the mass fraction of dissolved material in SSW. This would in turn change both the RCSS and the uncertainty associated with it. This approach would be necessary if we required the RCSS to always provide the best possible estimate of the mass fraction of the salts dissolved in standard seawater without additional adjustments. Below, we argue that even if at some time in the future an improved estimate for the composition of SSW is definitively determined, it would still be highly undesirable to modify the RC and along with it the RCSS.

There are two primary reasons that updating the RCSS should be avoided. First, we note that changes in Reference Salinity of order $0.002 \mathrm{~g} \mathrm{~kg}^{-1}$ (i.e., changes in Practical Salinity of order 0.002) are detectable in the ocean and salinity changes have been interpreted as indications of climate change (Levitus, 1989; Joyce et al., 1999; Wong et al., 1999; Dickson et al., 2002, 2003; Curry et al., 2003). Thus it is highly desirable for climate change studies to use a measure of salinity that will not change by this amount unless there is a true change in the salinity of seawater. Since the precision of Reference Salinity estimates is of this order, it provides a suitable measure if the definition of the RCSS remains unchanged. However, the uncertainty of order $0.05 \mathrm{~g} \mathrm{~kg}^{-1}$ as a measure of the mass fraction of dissolved material in seawater introduces the possibility that the RCSS could be revised several times by amounts considerably in excess of $0.002 \mathrm{~g} \mathrm{~kg}^{-1}$ as estimates of the mass fractions in RCSW are improved. Such changes recorded in data bases and in publications could be misinterpreted as signatures of climate change by investigators who are unaware of changes in the measurement scale. The potential for confusion is substantial and obviously undesirable. It should be avoided.

The second primary reason to avoid changes in the RCSS relates to the methods used to estimate the parameters in the TEOS-10 Gibbs potential function for seawater. The parameters in this function have been determined to provide correct results for SSW for specified values of Absolute Salinity, temperature and pressure, with the Absolute Salinity expressed on the current RCSS (recall that Reference Salinity is our best estimate of the Absolute Salinity of SSW). If this scale were to be changed, then the input salinity argument for the Gibbs function would be changed without any real change in the properties of a sample. Consequently, the Gibbs function would have to be modified to obtain the same thermodynamic properties with a modified salinity input. Although the required change is simple (it can be implemented by changing a single parameter) the possibility that some versions of computer code used to evaluate the Gibbs function would not be correctly updated is rather large. Even if the updates were somehow made in every existing version of the code, changes in the RCSS over time would require that different parameters be used in the Gibbs function for different time periods. Clearly the chance of introducing confusion through such changes is large.

Based on the above discussion, we conclude that it is desirable to avoid any changes in the definition of the RCSS. Fortunately, such changes should not be necessary. This is because the Reference Salinity is needed first to determine the salinity input to the Gibbs function and second as a measure of the mass fraction of dissolved material in seawater. Measurements on the current scale can serve both purposes very well. As already noted, maintenance of a fixed RCSS is desirable for applications of the Gibbs function to estimate the density and other thermodynamic properties of SSW since the Gibbs function has been constructed to provide correct results with the salinity specified on the RCSS. So the only concerns are related to use of the RCSS to provide a measure of the true mass fraction of dissolved material in seawater.

There is the possibility of a small change in the best estimate of mass fraction absolute salinity of SSW at some time in the future. For rare applications in which the error incurred by using the current scale to estimate the mass fraction might be significant, a correction could be made. This could be achieved by multiplying the Reference Salinity determined on the current scale by the ratio of the revised estimate of the absolute salinity of KCl-normalized SSW (from the 1970s) to the current estimate of $35.16504 \mathrm{~g} \mathrm{~kg}^{-1}$. Note that by avoiding repeated updates over time, a single correction factor will be applicable to all archived measurements. One of the very firm recommendations of the Intergovernmental Oceanographic Commission (IOC), the Scientific Committee on Ocean Research (SCOR) and the International Association for the Physical Sciences of the Oceans (IAPSO) in endorsing the use of TEOS-10 was that Practical Salinity 
should continue to be archived in national data bases (see IOC et al., 2010). This practice of storing results for a measured quantity but publishing results based on another related quantity is analogous to the present practice of archiving in situ temperature even though potential temperature is used for most analyses. This recommendation of IOC et al. (2010) is primarily intended to avoid confusion in data bases but it also means that the influence of any modifications of our best mass fraction estimates will be easily and consistently applied to both future data and past data that has been archived since Practical Salinity was defined 3 decades ago. In fact, since Practical Salinity is related to Chlorinity by the simple relation $S_{\mathrm{P}}=1.80655 \mathrm{Cl}$, any improvement in mass fraction estimates will also be easily applied to all of the Chlorinity data collected during the century before the introduction of Practical Salinity.

\section{The characterization of seawaters of arbitrary composition}

\subsection{Salinity variables for the representation of arbitrary seawater}

The differences between the compositions of SSW and RCSW are important in accurately determining the true absolute salinity of SSW, and would therefore be important in (e.g.) determining the best possible estimate of the total salt content of the oceans. On the other hand, the Gibbs function has been defined based on salinity measurements represented on the RCSS so the thermodynamic properties of SSW determined from the Gibbs function will be accurate even if the RCSS provides a slightly incorrect estimate of the mass fraction of dissolved material in SSW. However, as seawater circulates within the world oceans, its composition undergoes additional changes due to biogeochemical processes. The magnitudes of these changes are generally smaller than our uncertainty in the absolute salinity of SSW, but these anomalies are systematic and measurable, and their neglect results in errors in the representation of geographic changes in the thermodynamic properties of seawater. In contrast to any inaccuracies associated with the RCSS, these anomalies cannot be accounted for in the determination of the Gibbs function for SSW and they cannot be corrected for through a uniform scale factor applied to salinity estimates. In particular, their neglect results in systematic errors in basin-scale density gradients, and thus in inferred basin-scale transports. Consequently, it is important to consider how these anomalies can be characterized. In this section, we discuss how the composition of seawater changes, and different methods of incorporating these changes in measures of salinity that can be used to describe arbitrary seawaters.

We limit consideration to changes that will affect salinities at amounts larger than about $0.001 \mathrm{~g} \mathrm{~kg}^{-1}$. Anomalies associated with the carbonate system (positive and negative) tend to be largest due to the influences of air-sea exchange and biological cycling (Brewer and Bradshaw, 1975;
Pawlowicz, 2010). Their effects on the components of the $\mathrm{RC}$ can be adequately parameterized using just the total alkalinity (TA) and dissolved inorganic carbon (DIC) contributions, although they typically result in changes to the relative concentrations of all components of the carbonate system. In addition, there may be anomalies for species that are not present in the RC. These include nutrients, of which the most significant are silicic acid and nitrate. Fortunately, TA, $\mathrm{DIC}, \mathrm{Si}(\mathrm{OH})_{4}$ and $\mathrm{NO}_{3}^{-}$are all routinely measured in hydrographic programs. Finally, the actual composition anomaly must involve parameters that are not routinely measured, since arbitrary changes in TA and $\mathrm{NO}_{3}^{-}$must be compensated in some way to preserve charge balance. The most important process contributing to changes in TA in the deep ocean is likely the dissolution of $\mathrm{CaCO}_{3}$ (Sarmiento and Gruber, 2006), although other processes (e.g., sulfate reduction; Chen, 2002) may be at work, particularly in coastal and marginal seas. Pawlowicz (2010) chooses to balance charge in his model through the addition or removal of $\mathrm{Ca}^{2+}$ with the caveat that other processes are recognized to be important at least under some conditions. Comparison with observations reveals that the resulting estimates of $\mathrm{Ca}^{2+}$ are accurate to within about $0.8 \mathrm{mg} \mathrm{kg}^{-1}$.

Pawlowicz et al. (2010) use the above approach in a model study; they represent the major contributions to composition anomalies relative to SSW by specifying the anomalies in four components: TA, DIC, $\mathrm{NO}_{3}^{-}$and $\mathrm{Si}(\mathrm{OH})_{4}$, with anomalies in $\mathrm{Ca}^{2+}$ estimated from the requirements of charge balance. The largest anomalies occur in the North Pacific. To motivate the following discussion we refer to Table 1a and $\mathrm{b}$ where numerical values for the different salinity variables that we are about to discuss are provided for a North Pacific scenario. A full description of this table will be provided below, but it is useful to note at this stage that the numerical differences between the different salinity variables are of order $0.01 \mathrm{~g} \mathrm{~kg}^{-1}$, significantly larger than the precision with which Practical Salinity is measured $\left(0.002 \mathrm{~g} \mathrm{~kg}^{-1}\right)$.

We assume throughout our discussion that the dissolved material in a seawater sample consists of a component with the composition of SSW plus anomalies from this composition as discussed above. To be more specific, we must specify a representation of SSW from which composition anomalies can be determined. The RC was defined as a representation of SSW and it would thus seem reasonable to determine composition anomalies from this reference. However, as more information becomes available about the composition of SSW, better approximations for SSW will be obtained. Thus although there is no need to update the RCSS (and indeed important reasons not to do so, as discussed in Sect. 3.2), anomalies should be determined relative to the best available estimate of SSW composition rather than from the RC. We follow Pawlowicz (2010) and Pawlowicz et al. (2010) and represent SSW by the reference state referred to as SSW76 for the purpose of dealing with anomalies. 
Table 1. Salinity corrections for water from the deep North Pacific, with $\delta \rho_{\mathrm{R}}=0.015 \mathrm{~kg} \mathrm{~m}^{-3}$, normalized to (a) $S_{\mathrm{R}}=35 \mathrm{~g} \mathrm{~kg}{ }^{-1}$, and (b) $S_{*}=35 \mathrm{~g} \mathrm{~kg}^{-1} . \delta \rho_{\mathrm{R}}=\rho-\rho_{\mathrm{R}}$ is the estimated difference between the true density and the density evaluated from the Reference Salinity using the TEOS-10 Gibbs function. The corresponding Density Salinity anomaly $\delta S_{\mathrm{R}}{ }^{\text {dens }}$ (often denoted $\delta S_{\mathrm{A}}$ in other papers) is given by $\delta S_{\mathrm{R}}{ }^{\text {dens }}=\delta \rho_{\mathrm{R}} /\left(\rho_{\mathrm{R}} \beta_{\mathrm{R}}\right)$. The relations given in the second column are derived from formulae given in Pawlowicz et al. (2010) (see also IOC et al., 2010).

\begin{tabular}{|c|c|c|c|}
\hline (a) Salinity measure & $\begin{array}{l}\text { Anomaly relation } \\
\text { to } \delta S_{\mathrm{R}}^{\text {dens }}\end{array}$ & Value & $\begin{array}{c}\text { Offset from } \\
S_{\mathrm{R}} /(\mathrm{g} / \mathrm{kg})\end{array}$ \\
\hline$S_{\mathrm{P}}$ (Practical Salinity) & - & 34.836 & -0.164 \\
\hline$S_{\mathrm{R}}=(35.16504 / 35) S_{\mathrm{P}}$ (Reference Salinity) & - & $35.000 \mathrm{~g} / \mathrm{kg}$ & - \\
\hline$S_{*}=S_{\mathrm{R}}+\delta S_{\mathrm{R}}^{*}$ (Preformed Salinity) & $S_{*}-S_{\mathrm{R}} \approx-0.35 \delta S_{\mathrm{R}}^{\mathrm{dens}}$ & $34.993 \mathrm{~g} / \mathrm{kg}$ & -0.007 \\
\hline$S_{\mathrm{A}}^{\mathrm{dens}}=S_{\mathrm{R}}+\delta S_{\mathrm{R}}^{\mathrm{dens}}$ (Density Salinity) & $S_{\mathrm{A}}^{\mathrm{dens}}-S_{\mathrm{R}} \approx 1.0 \delta S_{\mathrm{R}}^{\mathrm{dens}}$ & $35.020 \mathrm{~g} / \mathrm{kg}$ & +0.020 \\
\hline$S_{\mathrm{A}}^{\text {soln }}=S_{\mathrm{R}}+\delta S_{\mathrm{R}}^{\text {soln }}$ (Solution Salinity) & $S_{\mathrm{A}}^{\text {soln }}-S_{\mathrm{R}} \approx 1.75 \delta S_{\mathrm{R}}^{\text {dens }}$ & $35.034 \mathrm{~g} / \mathrm{kg}$ & +0.034 \\
\hline$S_{\mathrm{A}}^{\mathrm{add}}=S_{\mathrm{R}}+\delta S_{\mathrm{R}}^{\text {add }}$ (Added-Mass Salinity) & $S_{\mathrm{A}}^{\mathrm{add}}-S_{\mathrm{R}} \approx 0.78 \delta S_{\mathrm{R}}^{\text {dens }}$ & $35.016 \mathrm{~g} / \mathrm{kg}$ & +0.016 \\
\hline (b) Salinity measure & $\begin{array}{l}\text { Anomaly relation } \\
\text { to } \delta S_{\mathrm{R}}^{\text {dens }}\end{array}$ & Value & $\begin{array}{c}\text { Offset from } \\
S_{*} /(\mathrm{g} / \mathrm{kg})\end{array}$ \\
\hline$S_{\mathrm{P}}$ (Practical Salinity) & - & 34.843 & -0.157 \\
\hline$S_{*}$ (Preformed Salinity) & - & $35.000 \mathrm{~g} / \mathrm{kg}$ & - \\
\hline$S_{\mathrm{R}}=S_{*}+\delta S_{*}^{\mathrm{R}}$ (Reference Salinity) & $S_{\mathrm{R}}-S_{*} \approx 0.35 \delta S_{\mathrm{R}}^{\text {dens }}$ & $35.007 \mathrm{~g} / \mathrm{kg}$ & +0.007 \\
\hline$S_{\mathrm{A}}^{\mathrm{dens}}=S_{*}+\delta S_{*}^{\text {dens }}$ (Density Salinity) & $S_{\mathrm{A}}^{\text {dens }}-S_{*} \approx 1.35 \delta S_{\mathrm{R}}^{\text {dens }}$ & $35.027 \mathrm{~g} / \mathrm{kg}$ & +0.027 \\
\hline$S_{\mathrm{A}}^{\text {soln }}=S_{*}+\delta S_{*}^{\text {soln }}$ (Solution Salinity) & $S_{\mathrm{A}}^{\text {soln }}-S_{*} \approx 2.1 \delta S_{\mathrm{R}}^{\text {dens }}$ & $35.041 \mathrm{~g} / \mathrm{kg}$ & +0.041 \\
\hline$S_{\mathrm{A}}^{\mathrm{add}}=S_{*}+\delta S_{*}^{\text {add }}$ (Added-Mass Salinity) & $S_{\mathrm{A}}^{\mathrm{add}}-S_{*} \approx 1.13 \delta S_{\mathrm{R}}^{\text {dens }}$ & $35.023 \mathrm{~g} / \mathrm{kg}$ & +0.023 \\
\hline
\end{tabular}

The considerations leading to the definition of SSW76 are discussed in detail by Pawlowicz (2010) and Pawlowicz et al. (2010). Briefly, both the RC and SSW76 are based primarily on analyses of SSW done in the 1970s. However, the borate and carbonate components represent significant contributions to the composition of SSW that were not systematically investigated and MFWM and Pawlowicz (2010) adopt different choices for these components. MFWM estimate these components under the assumption of equilibrium with atmospheric conditions at $25^{\circ} \mathrm{C}$ whereas Pawlowicz (2010) sets the DIC content of SSW76 to force the density to match that of in situ North Atlantic surface water, and (scanty) information about the true DIC content of SSW. The result is that the DIC specified by Pawlowicz (2010) is $2080 \mu \mathrm{mol} \mathrm{kg}-1$, significantly higher than the RC value of $1963 \mu \mathrm{mol} \mathrm{kg}^{-1}$. Correspondingly, the estimated mass fraction of dissolved material in KCl-normalized seawater is increased from $35.16504 \mathrm{~g} \mathrm{~kg}^{-1}$ to $35.17124 \mathrm{~g} \mathrm{~kg}^{-1}$. In this context, it is noteworthy that Brewer and Bradshaw (1975) determined the DIC content of SSW batch P61 to be $2238 \mu \mathrm{mol} \mathrm{kg}^{-1}$ and Millero et al. (1976b, 1978) report a value of $2226 \mu \mathrm{mol} \mathrm{kg}-1$ in SSW used to determine the equation of state. Although there is significant uncertainty associated with the carbonate components of SSW, it is very likely that the value of DIC corresponding to SSW76 is more representative of the analysed batches of SSW than the value corresponding to the $\mathrm{RC}$; this choice also simplifies the equations used to model interrelationships between the different salinity variables by avoiding the need to introduce offsets in the relations presented in Table $1 \mathrm{a}$ and $\mathrm{b}$.

Following the approach used for the RC, we represent SSW76 by exact mole fractions at the reference conditions of atmospheric pressure and $25^{\circ} \mathrm{C}$. For SSW76, we include the 16 main non-zero sea salt constituents listed in Table 2 of Pawlowicz (2010), $x_{a}^{76}>0, a=1,2, \ldots, 16$. Let $m_{a}>0$ represent the molality (moles/(kg solvent)) of species $a$ in a sample of SSW76. Since chloride is an approximately conserved constituent, we choose to use it as a measure of the component of dissolved material associated with SSW. If $x_{C l}^{76}$ represents the mole fraction of chloride in SSW76 and $m_{C l}$ represents the chloride molality of the particular solution under consideration, then the molality of component $a$ associated with SSW76 is given by $m_{C l} \times x_{a}^{76} / x_{C l}^{76}$ and the molal composition anomaly for species $a$ is $\delta m_{a}=m_{a}-m_{C l} \times x_{a}^{76} / x_{C l}^{76}$. In addition, there may be anomalies for species such as nutrients that are not present in SSW76, for which $\delta m_{a}=m_{a}$, $a>16$. Although we use SSW76 to estimate the magnitude of anomalies from Standard Seawater, we note that the salinity 
argument of the Gibbs function must be expressed on the RCSS which was determined using the RC. In practice, salinity will be determined from Reference Salinity plus anomalies in observational studies. Reference Salinity is defined using Eq. (8) so it is automatically expressed on the RCSS. Strictly speaking, the salinity anomalies determined by the formulae of Pawlowicz et al. (2010) should be multiplied by the factor 35.16504/35.17124 to express them on the RCSS, but this adjustment is entirely negligible for the small anomalies that occur in the open ocean.

To proceed further, we must carefully define what is meant by terms like "Absolute Salinity" when composition anomalies are present. This has not been done rigorously in previous publications.

The approach of Millero and co-workers has been to argue that changes in the mass fraction of dissolved material in seawater relative to $S_{\mathrm{R}}$ are adequately approximated by $\delta S_{\mathrm{A}}=\left(\rho-\rho_{\mathrm{R}}\right) /\left(\beta_{\mathrm{R}} \rho_{\mathrm{R}}\right)$ where $\beta_{\mathrm{R}}$ and $\rho_{\mathrm{R}}$ are the haline contraction coefficient and density at $S=S_{\mathrm{R}}$ determined from EOS-80 or TEOS-10 (the differences are negligible in this context). This approximation for the mass fraction of dissolved material is now referred to as Density Salinity and denoted by $S_{\mathrm{A}}^{\text {dens }}$ with the increment $\delta S_{\mathrm{A}}$ denoted by $\delta S_{\mathrm{R}}^{\text {dens }}$. The approach is supported by previous work (Millero, 1975; Chen and Millero, 1986) indicating that density changes of natural waters are affected primarily by the mass of added material, with the relative composition providing only a secondary effect. This definition naturally reverts to the existing definition of Reference Salinity as anomalies from SSW tend to zero since the density varies smoothly as composition anomalies tend to zero.

However, the limitations and biases of this approach are not well understood for seawater that includes anomalies from SSW. Previous verification has not systematically considered the range of composition variations that occur in the ocean and since the physical/chemical characteristics of different solutes can vary greatly, it is not really clear how Density Salinity is related to the mass fraction of dissolved material in seawater with arbitrary composition. Nor were changes in conductivity considered, which would affect Practical and Reference Salinity. In fact, we will see below that the difference between Density Salinity and Reference Salinity does not necessarily provide a good approximation for the anomalies in the mass fraction of dissolved material in seawater. Thus, although it will be argued that Density Salinity is well-suited to most physical oceanographic applications, an alternative measure of salinity is required to provide a precise measure of the mass fraction of material dissolved in seawater.

To develop a more rigorous definition of mass fraction salinity that will apply in the presence of composition anomalies and agree with the definition established in MFWM when no anomalies are present, we first re-examine the procedure followed by MFWM for SSW. The basic principles used to determine the Absolute Salinity of SSW are:
1. Addition or removal of pure water (i.e. dilution or evaporation) until $S_{\mathrm{P}}=35.000$ (or equivalently $\left.C l=19.374 \mathrm{~g} \mathrm{~kg}^{-1}\right)$,

2. Adjustment of the sample to chemical equilibrium at the reference conditions, $t=25^{\circ} \mathrm{C}$ and $P=101325 \mathrm{~Pa}$, without exchange of mass, under which conditions the Absolute Salinity of the sample can be determined from Eqs. (2) and (3), and

3. Determination of the Absolute Salinity of the original sample as the mass of dissolved material in the adjusted sample divided by the total mass of the original sample.

The obvious first steps in any definition of Absolute Salinity for anomalous compositions are then to standardize the concentration and adjust to equilibrium conditions at $t=25^{\circ} \mathrm{C}$ and $P=101325 \mathrm{~Pa}$. Unfortunately a precise adjustment to the conditions used for SSW is not possible because the chemical equilibria in the solution will inevitably be affected to some degree by the anomalous solute. However, operationally effective definitions are possible. Below, we discuss a conceptual approach followed by operationally practical approaches.

A crude standardization could be achieved simply by adjusting the Chlorinity of the solution to $19.374 \mathrm{~g} \mathrm{~kg}^{-1}$. In this case $S_{\mathrm{P}}$ would not in general be equal to 35.000 as it would for SSW because of the influence of composition anomalies on conductivity. Also, the total mass of solution, and hence the Chlorinity, is influenced by the presence of anomalous material so this approach to standardization is imprecise and will be inaccurate for large anomalies. A normalization approach that is less affected by composition anomalies can be achieved (at least conceptually or in numerical calculations) by adjusting the chloride molality, the total number of moles of chloride per $\mathrm{kg}$ of solvent, instead of Chlorinity. Unlike Chlorinity, the chloride molality is not influenced by the addition of anomalous solute that does not react with water; there is a weak influence if the added solutes react with water since they reduce the amount of water by a small amount.

It should be noted here that the separation between what is pure water and what is dissolved material is not totally clear, but this is not a serious issue at the level of accuracy that we currently require $(\sim 1 \mathrm{ppm}$ in density and salinity). In particular, one might question whether $\mathrm{H}_{3} \mathrm{O}^{+}$(the form that $\mathrm{H}^{+}$actually takes in water) and $\mathrm{OH}^{-}$are solute or solvent but it makes little difference at this level of accuracy. We have already noted that $\mathrm{OH}^{-}$is included as solute in the RC, but its mass fraction is just $0.08 \mathrm{mg} \mathrm{kg}^{-1}$ so its contributions to density and salinity are negligible. Given this estimate for $\mathrm{OH}^{-}$, an order of magnitude estimate for $\mathrm{H}_{3} \mathrm{O}^{+}$is easily determined. Since the dissociation constant of water is of order $10^{-14}$ (IAPWS, 2007), we have $\left[\mathrm{H}_{3} \mathrm{O}^{+}\right]\left[\mathrm{OH}^{-}\right]=K_{\mathrm{w}} \approx 10^{-14}(\mathrm{~mol} / \mathrm{l})^{2}$ and with a $\mathrm{pH}$ of order 8 (changes of order 0.1 associated with the choice of $\mathrm{pH}$ scale don't influence our order of magnitude estimate), it follows 
that $\mathrm{pOH}(=14-\mathrm{pH})$ is near 6 . Thus, the concentration of $\mathrm{H}_{3} \mathrm{O}^{+}$is roughly two orders of magnitude less than that of $\mathrm{OH}^{-}$. Hence although $\mathrm{H}_{3} \mathrm{O}^{+}$is considered as solute, it is not explicitly included in the RC because its contributions to density and salinity are far below the level of current concern.

For consistency with the normalization used in the definition of Reference Salinity, we normalize to the chloride molality of SSW76 that has a Chlorinity of 19.374 . This choice gives a chloride molality of $0.556642 \mathrm{~mol} \mathrm{~kg}^{-1}$ (=19.734631 g chloride per $\mathrm{kg} \mathrm{H}_{2} \mathrm{O}$ ). Thus for consistency with the definition of Absolute Salinity in the absence of composition anomalies, we add or subtract mass $m_{2}$ of pure water to adjust the original seawater sample of mass $m_{1}$ to a chloride molality of $0.556642 \mathrm{~mol} \mathrm{~kg}^{-1}$. We refer to this adjustment as chloride-normalization. We now divide the dissolved material (all material not in the pure water component of the solution) into two components. The first component includes the chloride component plus each of the other components of SSW76 in the same mole ratios as defined for SSW76. The mass of solute in a chloride-normalized solution of SSW76 is $36.45335 \mathrm{~g} /\left(\mathrm{kg} \mathrm{H}_{2} \mathrm{O}\right)((35.17124 \mathrm{~g}$ solute $) /(1000 \mathrm{~g}$ solution-35.17124 g solute) $)$. The second component includes all remaining dissolved material. Note that negative contributions from the chemical species in SSW are permitted in this second part although the total concentration of any species is non-negative. We now assume that the total mass of solute in this normalized solution can be determined and is $m_{\text {solute }}$. The mass of solvent in the normalized solution is then $m_{\text {solvent }}=m_{1}+\mathrm{m}_{2}-m_{\text {solute }}$. The total mass of the first component of solute is $m_{3}=0.03645335 \times m_{\text {solvent }}=$ $0.03645335 \times\left(m_{1}+m_{2}-m_{\text {solute }}\right)$ and that of the second component is $m_{4}=m_{\text {solute }}-0.03645335 m_{\text {solvent }}=1.03645335$ $m_{\text {solute }}-0.03645335\left(m_{1}+m_{2}\right)$. In principle $m_{4}$ may be negative (e.g., when some of a species in SSW is removed from solution).

Given the above information, the mass fraction definition of Absolute Salinity used by Millero et al. (2008a) can be extended to include composition anomalies in a (conceptually) very straightforward manner. The absolute salinity of the chloride-normalized solution can then be simply defined as the mass of material dissolved in the solution divided by the total mass of the solution $m_{\text {solute }} /\left(m_{1}+m_{2}\right)$. The mass fraction of dissolved material in the original solution is then determined as before under the assumption of salt conservation during the addition or removal of pure water and is given by $\left(1+m_{2} / m_{1}\right) \times m_{\text {solute }} /\left(m_{1}+m_{2}\right)=m_{\text {solute }} / m_{1}$ or $\left(m_{3}+m_{4}\right) / m_{1}$. We refer to this as the Solution Salinity, and denote it as $S_{\mathrm{A}}^{\text {soln }}$, where "soln" refers to the fact that the mass of dissolved material is determined after it reaches equilibrium in solution. This definition is consistent with the definition of Absolute Salinity given by MFWM (see Sect. 3 above) for SSW and uses the same basic approach to extend the definition to allow for composition anomalies.

The separation of solute into the two components introduced above is of interest in its own right. Since chloride does not take part in biogeochemical cycling and so is essentially a conservative variable, the component associated with the Reference Composition will be quasi-conservative following the ocean general circulation, analogous to other similarly constructed quasi-conservative tracers like $\mathrm{N}^{*}$ and NO* (Sarmiento and Gruber, 2006). It has mass fraction absolute salinity $S_{*}=m_{3} / m_{1}$ and will be referred to as the Preformed Salinity. $S_{*}$ is modified by exchanges of water at the ocean surface and by mixing in the ocean interior, but the effects of biogeochemical processes on it are deliberately excluded. It is thus an ideal baseline to which material is added by biogeochemical processes. The remainder of the solute is referred to as the anomalous part. Again, we note that it is possible for the "remainder" to be negative as in the case when some of a SSW species is removed from solution.

We emphasize that $S_{\mathrm{A}}^{\text {soln }}$ deals with a solution in equilibrium and treats all non-water components of seawater as dissolved material. Consequently, when new material is added to solution, the change in mass of the dissolved material may deviate from the added mass. Perhaps the most obvious example occurs when $\mathrm{CO}_{2}$ is dissolved in water to produce a mixture of $\mathrm{CO}_{2}, \mathrm{H}_{2} \mathrm{CO}_{3}, \mathrm{HCO}_{3}^{-}, \mathrm{CO}_{3}^{2-}, \mathrm{H}^{+}, \mathrm{OH}^{-}$and $\mathrm{H}_{2} \mathrm{O}$, with the relative proportions depending on dissociation constants that depend on temperature, pressure and $\mathrm{pH}$. Thus, the dissolution of a given mass of $\mathrm{CO}_{2}$ in pure water essentially transforms some of the water into dissolved material. Similar situations occur for other dissolved materials; some may also release water upon dissolution, such as certain calcium minerals.

In contrast to the case for Solution Salinity, it is sometimes useful to deal with the anomalous mass added to SSW directly. This is particularly true in laboratory experiments. If a mass $m_{\text {add }}$ of anomalous solute is added to a sample of KCl-normalized (or equivalently chloride-normalized) SSW of mass $m_{\text {ssw }}$ then a mass fraction absolute salinity may be defined as $\left(0.03517124 m_{\mathrm{ssw}}+m_{\mathrm{add}}\right) /\left(m_{\mathrm{ssw}}+m_{\mathrm{add}}\right)$, where $0.03517124 \mathrm{~m}_{\mathrm{ssw}}$ is the mass of dissolved material in the original sample of SSW, $m_{\text {add }}$ is the added mass of anomalous material and $m_{\mathrm{ssw}}+m_{\mathrm{add}}$ is the total mass of the final solution. We refer to this as Added-Mass Salinity, and denote it as $S_{\mathrm{A}}^{\text {add }}$. For Standard Seawater $S_{\mathrm{A}}^{\text {add }}$ is also consistent with the definition of Absolute Salinity for SSW given by MFWM since no mass is added in that case, but for seawater of anomalous composition the mass of anomalous solute is determined before it is added to the solution rather than after equilibrium conditions have been established for the new solution, as would be required for the Solution Salinity. Any chemical reactions of the added solute with the SSW solution are therefore not considered for Added-Mass Salinity. That is, neither precipitation of species nor redistributions between solvent and solute have any effect on Added-Mass Salinity. It is therefore conceptually very different from Solution Salinity and we will see below that it is also substantially different in practice.

Although the Added-Mass Salinity may be useful in the 
laboratory, it is not straightforward to estimate for seawater with anomalous composition that is sampled from the ocean. Even if we assume that the composition of the final equilibrium state is known, one must still estimate the mass of anomalous solute prior to any chemical reactions with SSW. Since equilibrium states are independent of their history, any combination of chemical species that irreversibly evolve to the given sample composition is a potential candidate for the computation of Added-Mass Salinity, which therefore is highly ambiguous for a given final solution. Additional information must therefore be provided to resolve this ambiguity if Added-Mass Salinity is to be determined for ocean seawater. Pawlowicz et al. (2010) provide an algorithm to achieve this estimate, at least approximately, once some assumptions about ocean biogeochemical processes are made. The details are substantially more complicated than those required for Solution Salinity and will not be reproduced here. The main point that we wish to emphasize is that the difference between Solution Salinity and Added-Mass Salinity lies in the treatment of the anomalous contributions and that (as illustrated in Table 1a and b) these differences are important at the level of precision being considered here. In either case, the Preformed Salinity $S_{*}$ can be uniquely determined from the chloride molality. However, the numerical values of the salinity anomalies $\delta S_{*}^{\text {soln }}$ and $\delta S_{*}^{\text {add }}$ which are added to Preformed Salinity $S_{*}$ to determine $S_{\mathrm{A}}^{\text {soln }}$ and $S_{\mathrm{A}}^{\text {add }}$ may differ significantly.

To illustrate the magnitude and range of the numerical variations between different measures of salinity, we consider an extreme example. Deepwater composition anomalies from SSW in the open ocean are largest at depth in the North Pacific. For KCl-normalized seawater, TA is increased relative to SSW values by about $150 \mu \mathrm{mol} \mathrm{kg}^{-1}$, and DIC by $300 \mu \mathrm{mol} \mathrm{kg}^{-1}$. $\mathrm{NO}_{3}^{-}$concentrations are as high as $40 \mu \mathrm{mol} \mathrm{kg}^{-1}$, and $\mathrm{Si}(\mathrm{OH})_{4}$ concentrations are as large as $170 \mu \mathrm{mol} \mathrm{kg}{ }^{-1}$. The corresponding increase in $\mathrm{Ca}^{2+}$ is inferred to be $95 \mu \mathrm{mol} \mathrm{kg}{ }^{-1}$ to balance charge. Maximum density anomalies relative to densities calculated using $S_{\mathrm{R}}$ and the TEOS-10 equation of state in this region are estimated to be about $0.015 \mathrm{~kg} \mathrm{~m}^{-3}$, both from direct measurements and using the model calculations of Pawlowicz et al. (2010). The approximate magnitude of the corrections to determine salinities of the different types defined above can be derived from this density anomaly using equations proposed by Pawlowicz et al. (2010). The corrections and the numerical values of the different salinities are shown in Table 1a and b. Table 1a shows the changes to the various salinity variables with respect to a Reference Salinity, while Table 1b shows the same salinity perturbations with respect to a Preformed Salinity. The salinity perturbations in Table 1a are appropriate for the estimation of various measures of absolute salinity when the Practical Salinity (and hence Reference Salinity) is available as a measured quantity (using, for example the lookup table of McDougall et al. (2009) to determine the corrections) while Table $1 \mathrm{~b}$ is relevant to the consideration of biogeochemical effects.

Importantly, the model study of Pawlowicz et al. (2010) shows that, for the anomalies arising from ocean biogeochemical processes, correlations between the anomalies of different constituents are strong enough in all ocean basins that the linear relations given in column 2 of Table 1 apply for all deep-ocean sites within an uncertainty of about $0.003 \mathrm{~g} \mathrm{~kg}^{-1}$, even though the exact nature of the composition anomalies that produce the density anomalies can vary with geographic location. If the details of the composition anomalies in TA, DIC, $\mathrm{NO}_{3}^{-}$and $\mathrm{Si}(\mathrm{OH})_{4}$ are known, then more accurate interrelationships can be derived using relatively simple formulas (Pawlowicz et al., 2010; IOC et al., 2010), two of which are reproduced below as Eqs. (9) and (10). In practice, measurements of conductivity and density, or of conductivity and concentrations of major nonconservative parameters (carbonate system and nutrients), along with a few assumptions about the nature of ocean biogeochemical processes, are enough to specify the full seawater system to a useful accuracy, including Density Salinity, Solution Salinity, Added-Mass Salinity and Preformed Salinity.

The largest deviations from Reference Salinity in Table 1a are for Practical Salinity, and it is largely this discrepancy that justifies the introduction of the Reference Salinity as a more accurate measure of absolute salinity. The next largest numerical offset from the Reference Salinity appears in Solution Salinity which is roughly one quarter as large as the offset for Practical Salinity. The final salinity increase for Solution Salinity is significantly larger than for Added-Mass Salinity due to the incorporation of $\mathrm{H}^{+}$and $\mathrm{OH}^{-}$into the anomalous non-conservative contributions to the dissolved material. The values for the Density Salinity $S_{\mathrm{A}}^{\text {dens }}$ and Added-Mass Salinity $S_{\mathrm{A}}^{\text {add }}$ are closest, and would generally lie (just) within typical measurement error of each other, a determination that is shown to also hold for a variety of laboratory results in Pawlowicz et al. (2010). The smallest deviation from Reference Salinity occurs for Preformed Salinity. However, even this change is about double the precision to which Reference Salinity can be determined through conductivity measurements. Tables $1 \mathrm{a}$ and $\mathrm{b}$ emphasize the fact that the single largest factor limiting our knowledge of the spatial variations of thermodynamic properties (like density) is a correct estimation of the effects of compositional variations.

Although no one salinity variable can fully characterize seawater with anomalous composition, the central importance of density to dynamical investigations of the ocean suggests that if a single salinity variable is required, then the Density Salinity is the most useful. However, attempts to use the Density Salinity as loosely defined at the beginning of this section lead almost immediately to a number of technical questions that are addressed in the next section. 


\subsection{The "Density Salinity" of seawater}

In Sect. 2 we noted that the Density Salinity equals the Reference Salinity by construction for the special case of SSW and therefore reproduces the MFWM estimate of the mass fraction of dissolved material in seawater in this case. It is also intended to be a useful measure of salinity effects in the general case when composition anomalies are present but this depends on whether its use with the Gibbs function for SSW returns sufficiently accurate results for density and other thermodynamic quantities over the range of oceanographic conditions. Here we more rigorously define the Density Salinity as a numerical measure that returns the correct value of density when used as an argument of the Gibbs function at a selected $T-P$ reference point, and show that the density values returned at other temperatures and pressures are sufficiently accurate for practical usage. We then discuss alternative methods by which it can be estimated that will be useful in practice.

First, note that for SSW, the TEOS-10 density is given by

$\rho=\frac{1}{v}=\frac{1}{g_{P}\left(S_{\mathrm{R}}, T, P\right)}$,

where $v$ is the specific volume, $g$ is the Gibbs function for SSW (Feistel, 2008; IAPWS, 2008) and the subscript $P$ indicates partial differentiation with respect to pressure at constant salinity and temperature. For SSW, evaluating Eq. (4) at fixed $S_{\mathrm{R}}$ for different values of $T$ and $P$ will determine the correct values of $\rho$ for a fixed seawater sample. Thus, measurement of $\rho$ at any specified values of $T, P$ and subsequent inversion of Eq. (4) to determine $S_{\mathrm{R}}$ will return the unique value of $S_{\mathrm{R}}$ appropriate to the sample. This unique value of $S_{\mathrm{R}}$ is referred to as the Density Salinity of the SSW sample and is represented by the symbol $S_{\mathrm{A}}^{\mathrm{dens}}$. We wish to extend this definition to apply to seawater samples of arbitrary composition, but in this case the values of $S_{\mathrm{R}}$ determined by measurements of the same sample at different values of $T$ and $P$ are not guaranteed to be the same since thermal expansion and compressibility may be influenced by the presence of composition anomalies in ways that are not accounted for by Eq. (4). Consequently, to use this procedure to define a unique representation of salinity for a seawater sample of arbitrary composition, we must specify reference conditions at which $S_{\mathrm{A}}^{\mathrm{dens}}$ is to be determined. For reference conditions, we choose $t=25^{\circ} \mathrm{C}$ and $P=101325 \mathrm{~Pa}$. Thus, for a sample of general composition, with density $\rho$ at $t=25^{\circ} \mathrm{C}$ and $P=101325 \mathrm{~Pa}$, the Density Salinity $S_{\mathrm{A}}^{\text {dens }}$ is defined by the implicit equation

$$
\rho=\frac{1}{g_{P}\left(S_{\mathrm{A}}^{\text {dens }}, 298.15 \mathrm{~K}, 101325 \mathrm{~Pa}\right)} \text {. }
$$

In general, Eq. (5) must be solved numerically, as discussed in Feistel et al. (2010a). This is straightforward because it involves the zero of a monotonic function; a routine to perform the inversion is provided in the Sea-Ice-Air library (Wright et al., 2010). $S_{\mathrm{A}}^{\text {dens }}$ is thus guaranteed to provide the correct value of density when used as an input to the Gibbs function representation, for any seawater composition at the reference values of temperature and pressure. Below, we show that if Density Salinity is defined by Eq. (5), then it can also be used as the salinity argument in Eq. (4) to determine reliable estimates of the density at other values of temperature and pressure. The demonstration of this point also shows that the value determined for Density Salinity is not sensitive to the choice of reference conditions so although a choice must be specified for strict consistency, this choice is not important in practice.

To be more specific regarding the need to specify reference conditions for a seawater sample of arbitrary composition, we note that if the density is correctly determined at any reference point $T_{\mathrm{R}}, P_{\mathrm{R}}$, then we can determine the density at any other temperature and pressure from the equation

$\rho^{\text {true }}\left(S_{\mathrm{A}}^{\text {dens }}, T, P\right)=\rho\left(S_{\mathrm{A}}^{\text {dens }}, T_{\mathrm{R}}, P_{\mathrm{R}}\right)+\int_{T_{\mathrm{R}}}^{T} \frac{\partial \rho}{\partial T}\left(S_{\mathrm{A}}^{\text {dens }}, t, P_{\mathrm{R}}\right) d t$

$+\int_{P_{\mathrm{R}}}^{P} \frac{\partial \rho}{\partial P}\left(S_{\mathrm{A}}^{\mathrm{dens}}, T, p\right) d p$

where the partial derivatives with respect to temperature and pressure are the true values for the water sample. When the Gibbs function is used to evaluate the density, away from the reference conditions, these derivatives are effectively replaced by the corresponding derivatives for Standard Seawater. The error associated with using the Gibbs function to determine density for an arbitrary seawater sample can therefore be expressed as

$$
\begin{aligned}
& \Delta \rho\left(S_{\mathrm{A}}^{\text {dens }}, T, P\right)=\int_{T_{\mathrm{R}}}^{T} \frac{\partial\left(\rho-\rho^{\mathrm{SSW}}\right)}{\partial T}\left(S_{\mathrm{A}}^{\mathrm{dens}}, t, P_{\mathrm{R}}\right) d t \\
& +\int_{P_{\mathrm{R}}}^{P} \frac{\partial\left(\rho-\rho^{\mathrm{SSW}}\right)}{\partial P}\left(S_{\mathrm{A}}^{\text {dens }}, T, p\right) d p
\end{aligned}
$$

where $\rho^{\mathrm{SSW}}$ is the density determined by the Gibbs function formulation for SSW.

Equation (7) clearly reveals the source of the errors that we wish to consider. Unfortunately, very little experimental work has been done on the influence of composition anomalies on the thermal expansion or compressibility of seawater. However, the FREZCHEM model (Marion and Kargel, 2008; Feistel and Marion, 2007; Feistel et al., 2010b), which is based on Pitzer equations for aqueous electrolyte solutions, can be used to estimate the magnitude of the errors indicated by Eq. (7). These model calculations are subject to considerable uncertainty since they are not validated by direct measurements, and the numerical results are affected by the details of the chosen compressibility parameterization. 
However, the basic results discussed below have also been confirmed using the LIMBETA model (Pawlowicz et al., 2010) with different parameterizations of compressibility effects. Thus, although details are uncertain, the model calculations provide a useful indication of the magnitude of the effects of composition anomalies on the evaluation of density using the Gibbs function for SSW.

To provide a relevant example, we consider the effect of anomalies similar to those observed at depth in the North Pacific where the largest known deep ocean anomalies are found. Two (numerical) samples of seawater are created, the first representing Standard Seawater as discussed by Feistel and Marion (2007) and the second including composition anomalies corresponding to North Pacific Intermediate Water (Sect. 4.1 and Pawlowicz et al., 2010). The concentration of solute in the SSW sample is specified to give $S_{\mathrm{R}}=35 \mathrm{~g} \mathrm{~kg}^{-1}$. NPIW anomalies are then added to a duplicate sample to give a density anomaly of approximately $0.015 \mathrm{~g} \mathrm{~m}^{-3}$, similar to the maximum anomalies observed in the open ocean. Pure water is then added to this NPIW sample to adjust its density to match that of the original SSW sample at $t=25^{\circ} \mathrm{C}$, $P=101325 \mathrm{~Pa}$, so that the samples of SSW and slightly diluted NPIW have identical Density Salinities.

Using the algorithms included in the FREZCHEM model, modified to represent a closed system with respect to $\mathrm{CO}_{2}$ exchange, the density changes predicted for both the SSW sample and the diluted NPIW sample are now determined for $t$ between $-2{ }^{\circ} \mathrm{C}$ and $40^{\circ} \mathrm{C}$ and $P$ between $10^{5} \mathrm{~Pa}$ and $10^{8} \mathrm{~Pa}$ (roughly between the surface and $10000 \mathrm{~m}$ below the ocean's surface), and the density differences between the two samples are determined. If the temperature is below the freezing point of one or both samples then results are determined for metastable liquid states. The results are shown in Fig. 1 and indicate that the density difference between the two samples varies smoothly and is less than $0.2 \mathrm{~g} \mathrm{~m}^{-3}$ over the full range of temperature and pressure conditions considered. This difference is at least a factor of ten smaller than the smallest density differences that can be routinely detected using a densimeter and is certainly negligible for the present purpose. Uncertainties associated with the formulation of FREZCHEM (see, e.g., Marion et al., 2005) may significantly alter the details of Fig. 1, but they would not alter the main result that the errors associated with using the TEOS-10 Gibbs function, with $S_{\mathrm{A}}^{\text {dens }}$ as the salinity argument, to estimate density changes over the Neptunian range of temperature and pressure changes are negligible. Experimentation with the LIMBETA model (Pawlowicz et al., 2010) confirms that even with different choices for uncertain parameterizations, the errors always remain less than $1 \mathrm{~g} \mathrm{~m}^{-3}$, which is still negligible for the present purpose.

FREZCHEM has also been used to estimate the corresponding anomalies in the specific heat capacity at atmospheric pressure and in the activity potential for the full Neptunian ranges of temperature and pressure. The differences between the specific heat capacity results for NPIW and

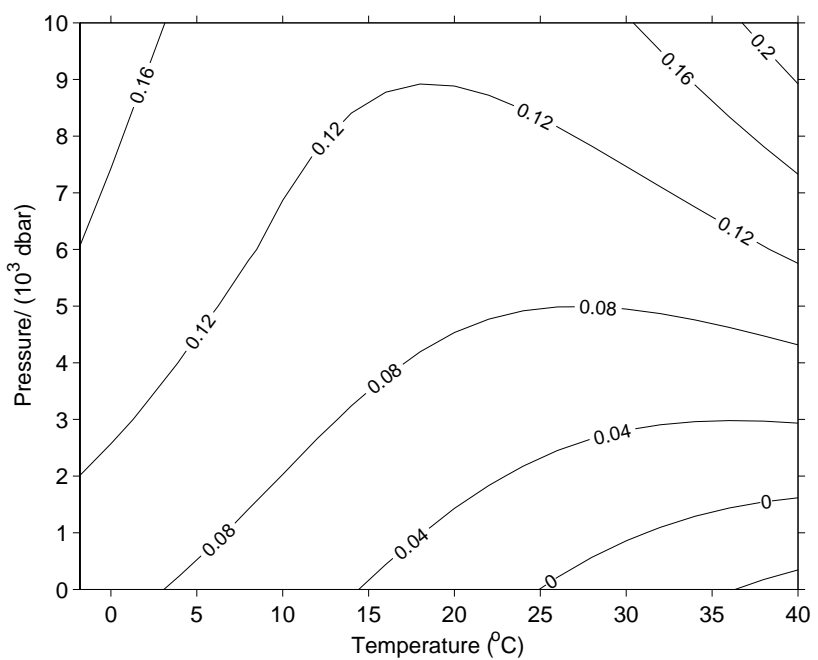

Fig. 1. The estimated density difference $\left(\mathrm{g} \mathrm{m}^{-3}\right.$, $\left.\mathrm{ppm}\right)$ between two water samples used to represent NPIW and SSW that have been adjusted to give identical densities at $t=25^{\circ} \mathrm{C}$ and $P=101325 \mathrm{~Pa}$. These estimates are obtained using the FREZCHEM model and should be treated as rough estimates. However, even given the associated uncertainties, the differences are negligible compared to the total density changes associated with composition anomalies in the open ocean.

SSW with the same Density Salinity are between 0.023 and $0.029 \mathrm{~J} \mathrm{~kg}^{-1} \mathrm{~K}^{-1}$ and are entirely negligible compared to the experimental uncertainty of $0.5 \mathrm{~J} \mathrm{~kg}^{-1} \mathrm{~K}^{-1}$ for the specific heat capacity of pure water. In fact, even the total changes in heat capacity for an Absolute Salinity change of $0.025 \mathrm{~g} \mathrm{~kg}^{-1}$ is only about $0.12 \mathrm{~J} \mathrm{~kg}^{-1} \mathrm{~K}^{-1}$, which is itself negligible compared to the measurement uncertainty, so we conclude that the influence of composition anomalies on specific heat capacity is safely neglected. For the activity potential, total differences are between $3.5 \times 10^{-5}$ and $6 \times 10^{-5}$ with the largest values occurring at the highest temperatures and only a relatively weak dependence on pressure. These values are again negligible compared to the variations for each water sample that are of order $3 \times 10^{-2}$ (values are in the range -0.40 to -0.43 for the range of oceanographic conditions considered).

Another important quantity to represent accurately is the "heat content" of seawater, which is required in long-term integrations of climate models. The quantity that is very closely proportional to the "heat content" of seawater is Conservative Temperature $\Theta$ (McDougall, 2003) being proportional to potential enthalpy with a reference pressure of zero dbar (i.e. zero sea pressure, or an absolute pressure of $101325 \mathrm{~Pa}$ ). In appendix A.21 of IOC et al. (2010) it is shown that Conservative Temperature $\Theta$ is quite insensitive to small changes in salinity. There it is shown that an uncertainty in the salinity argument of the Gibbs function of $0.025 \mathrm{~g} \mathrm{~kg}^{-1}$ leads to an uncertainty in $\Theta$ of only about 
$0.5 \mathrm{mK}$, which is negligible for present purposes. The errors associated with using the SSW Gibbs function to evaluate the Conservative Temperature with the Density Salinity as an input will be even smaller.

Estimation of the influence of composition anomalies on other quantities is complicated by the almost complete lack of experimental results on the thermodynamic properties of seawater in the presence of known composition anomalies. Feistel et al. (2010b) develop an approach that allows them to estimate the full range of thermophysical properties in the presence of small composition anomalies relative to SSW. Using the FREZCHEM model (Marion and Kargel, 2008), "data" is generated for the specific volume, heat capacity and activity potential of seawater that includes the composition anomaly of interest and this data is then used to determine the Gibbs function for the anomalous seawater (Feistel and Marion, 2007; Feistel et al., 2010b). Note that although the FREZCHEM "data" is limited to only three properties, once the Gibbs function is obtained a much broader range of properties is easily considered. Compared to the significant experimental and numerical effort required for the construction of a highly accurate Gibbs function for a particular solute composition such as SSW (Feistel, 2008), this Gibbs-Pitzer approach is the currently easiest practical method to estimate arbitrary thermodynamic property anomalies with sufficient accuracy.

Although a Gibbs function that explicitly accounts for the composition anomalies present in the open ocean has not yet been developed, Feistel et al. (2010b) have formulated a composition-dependent Gibbs function for the special case of Baltic Sea water in which the primary anomaly is due to the addition of calcium carbonate to SSW. They consider the influence of composition anomalies on several quantities for this special case. Their Fig. 18 shows that the density error $\Delta \rho$ corresponding to Eq. (7) for typical Baltic seawater anomalies depends strongly on the brackish salinity but is less than $5 \mathrm{~g} \mathrm{~m}^{-3}$ for the full range of conditions considered, i.e., for $P=101325 \mathrm{~Pa}, 0{ }^{\circ} \mathrm{C}<t<25^{\circ} \mathrm{C}$ and solute anomalies between 0 and approximately $100 \mathrm{~g} \mathrm{~m}^{-3}$. Note that the maximum solute anomalies in the Baltic are nearly 7 times as large as those in NPIW. Compared to the true density anomaly $\delta \rho_{\mathrm{R}}$ associated with the presence of anomalous solute, the relative error $\left|\Delta \rho / \delta \rho_{\mathrm{R}}\right|$ is greater than $10 \%$ (approaching $16 \%$ ) only near $S_{\mathrm{A}}^{\text {dens }}=35 \mathrm{~g} \mathrm{~kg}^{-1}$ where both the true density anomaly and the absolute error tend to zero. Thus use of Density Salinity represents a useful approach to account for the influence of composition anomalies on density even in the presence of the larger composition anomalies found in the Baltic.

Feistel et al. (2010b) also consider uncertainties associated with using Density Salinity as the salinity argument of the SSW Gibbs function for other thermodynamic properties of Baltic Sea water. They find that this approach consistently provides improved results compared to those obtained using Reference Salinity, which was estimated using the LSEA_DELS model to determine the anomalous conduc- tivity of Baltic Sea water (Pawlowicz, 2008, 2010). The improvements vary significantly for different properties, but in no case are results degraded. For only one of the several properties considered, namely the sound speed, was the deviation between the estimated anomaly and the result obtained using Density Salinity in the SSW Gibbs function found to significantly exceed the experimental uncertainty.

We conclude that for the most demanding applications that we are aware of, Density Salinity is very well-suited for use as the salinity argument of the Gibbs function since it produces accurate results for both density and heat-related quantities. Thus the form of absolute salinity best suited to extend the definition of the Absolute Salinity of SSW to seawaters with anomalous composition is the Density Salinity. In addition, the results for Baltic seawater anomalies show that this approach provides results within measurement uncertainties for all considered quantities except sound speed. The latter result is suggestive for general seawater anomalies, but has not been verified except for Baltic seawater anomalies.

\subsection{Operational aspects of Density Salinity}

The solution of Eq. (5) for an arbitrary seawater sample constitutes the definition of the Density Salinity, $S_{\mathrm{A}}^{\text {dens }}$ but results are insensitive to the reference values of $T$ and $P$. The most direct approach to determining the value of $S_{\mathrm{A}}^{\text {dens }}$ for a particular water sample is then to determine its density using an instrument such as a vibrating-tube densimeter (Wolf, 2008) or perhaps an optical salinity sensor (Grosso et al., 2010) to measure $\rho$ and invert Eq. (5) at the temperature and pressure at which the density is measured. To estimate the accuracy to which $S_{\mathrm{A}}^{\text {dens }}$ can be determined using Eq. (5) in practice, we first note that using a densimeter, density can be routinely measured to an accuracy of order $10 \mathrm{~g} \mathrm{~m}^{-3}$ (with a coverage factor of 2), and it is possible to reduce this uncertainty to less than $2 \mathrm{~g} \mathrm{~m}^{-3}$ at atmospheric pressure with careful use of the substitution method (Wolf, 2008; Feistel et al., 2010a). Given this uncertainty in density and the fact that the haline contraction coefficient for SSW is approximately 0.75 $\left(\mathrm{g} \mathrm{g}^{-1}\right)^{-1}$, we conclude that the above approach can be used to routinely make individual Density Salinity measurements with an accuracy of order $0.013 \mathrm{~g} \mathrm{~kg}^{-1}$ and that using the methodology described by Wolf (2008) this can be reduced to about $0.003 \mathrm{~g} \mathrm{~kg}^{-1}$, comparable to the precision of Practical Salinity measurements.

An important advantage of any approach using density to specify salinity is that density measurement results that are obtained by the substitution method (for example) are traceable to the SI (Seitz et al., 2010b). Although at present this linkage is still immature, the introduction of Density Salinity should facilitate future attempts to bring ocean salinity measurements within the general framework of physical standards. This also makes it more suitable for long-term monitoring than Practical Salinity alone because the accuracy of 
the latter is approximately one order of magnitude less than its precision (Seitz et al., 2010a).

The definition of $S_{\mathrm{A}}^{\text {dens }}$ using Eq. (5) is most useful when density, temperature and pressure are known and one wishes to calculate other thermodynamic properties of seawater. The Density Salinity can then be determined and used to estimate a wide range of thermodynamic properties as discussed by Feistel et al. (2010b) and Wright et al. (2010). Of course, measurements of density require some experimental effort and are not always available. Further, in applications such as numerical ocean circulation modelling the salinity is normally updated using a prognostic equation and then used to determine the density; a definition of $S_{\mathrm{A}}^{\text {dens }}$ that assumes knowledge of $\rho$ is not particularly useful for such applications. To use $S_{\mathrm{A}}^{\text {dens }}$ as an input to the Gibbs function in such cases, an alternative approach is required to estimate it. Three approaches to achieve this are discussed below.

The first approximation for $S_{\mathrm{A}}^{\text {dens }}$ is provided by the Reference Salinity

$S_{\mathrm{R}}=(35.16504 / 35) S_{\mathrm{P}} \mathrm{gkg}^{-1}$,

(Millero et al., 2008a) which neglects the generally small composition anomalies in seawater and therefore provides results essentially equivalent to past practice with the commonly used Practical Salinity $S_{\mathrm{P}}$. The extensions of the Practical Salinity Scale to cover $0<S_{\mathrm{P}}<2$ by Hill et al. (1986) and $42<S_{\mathrm{P}}<50$ by Poisson and Gadhoumi (1993), permit Eq. (8) to be directly applied over the full range $0<S_{\mathrm{P}}<50$. Note, however, that the high-salinity densities measured by Poisson and Gadhoumi 1993) possess larger uncertainties than originally estimated by the authors (Millero and Huang, 2009; Feistel, 2003, 2010). Use of this approximation in the Gibbs function already provides more and improved estimates of the thermodynamic properties of SSW than were previously available from EOS-80 (Fofonoff and Millard, 1983; Feistel, 2003, 2008, 2010).

A more sophisticated approach that can be used to provide improved estimates of the Density Salinity in the presence of composition anomalies is developed in McDougall et al. (2009) and used to determine a global atlas of $\delta S_{\mathrm{R}}^{\text {dens }}=S_{\mathrm{A}}^{\text {dens }}-S_{\mathrm{R}}$ (referred to as $\delta S_{\mathrm{A}}$ by McDougall et al., 2009). The method is based on semi-empirical results presented in a series of papers in which measured density anomalies are regressed onto the concentrations of other variables that are easier to measure (Millero and Kremling, 1976; Millero, 2000a; Millero et al., 1976a, b, 1978, 2008b, 2009; Feistel et al., 2010a, b).

McDougall et al. (2009) make use of Density Salinity estimates determined from direct density measurements using Eq. (5) as well as Reference Salinity estimates determined from conductivity measurements and composition anomaly estimates determined by various analytical measurement techniques. Using these results, $\delta S_{\mathrm{R}}^{\text {dens }}=S_{\mathrm{A}}^{\text {dens }}-S_{\mathrm{R}}$ is estimated and compared with the estimates of composition anomalies. A linear relation between the Density Salinity anomaly $\delta S_{\mathrm{R}}^{\text {dens }}$ and silicate anomalies is empirically determined, with different latitude-dependent proportionality constants in each ocean basin that all agree where they connect with the Southern Ocean. The root-mean-square variations of observed values about this empirical estimate vary with location but are typically of order $0.005 \mathrm{~g} \mathrm{~kg}^{-1}$, which should be compared to root-mean-square spatial variations of order $0.01 \mathrm{~g} \mathrm{~kg}^{-1}$ and maximum anomalies of order $0.015 \mathrm{~g} \mathrm{~kg}^{-1}$ for the Density Salinity anomaly itself (McDougall et al., 2009). The uncertainty estimate of $0.01 \mathrm{~g} \mathrm{~kg}^{-1}$ obtained using a coverage factor of 2 is already comparable with the uncertainty in individual estimates of $\delta S_{\mathrm{R}}^{\text {dens }}$ obtained directly from densimeter and CTD measurements. The second columns of Table $1 \mathrm{a}$ and $\mathrm{b}$ gives the various salinity anomaly measures in terms of the quantity tabulated by McDougall et al. (2009). The use of these in numerical modelling studies of present-day conditions is considered in Sect. 5.

The third method for estimating Density Salinity will be useful for studies in which salinity anomalies might be expected to change, as in paleoclimate or climate change simulations. In such cases, it is desirable to have expressions that relate to variables that can (eventually) be modelled rather than specified based on climatological conditions. This requires an alternative approach to that of McDougall et al. (2009) for the calculation of Density Salinity. For such purposes, the results of Pawlowicz et al. (2010) should prove useful. They show that Density Salinity anomalies relative to Reference Salinity $S_{\mathrm{R}}$ can be related to composition anomalies relative to SSW76 using the equation

$\delta S_{\mathrm{R}}^{\text {dens }} /\left(\mathrm{mg} \mathrm{kg}^{-1}\right)=55.6 \Delta \mathrm{TA}+4.7 \Delta \mathrm{DIC}$

$$
+38.9 \Delta\left[\mathrm{NO}_{3}^{-}\right]+50.7 \Delta\left[\mathrm{Si}(\mathrm{OH})_{4}\right]\left(\mathrm{mmolkg}^{-1}\right),
$$

with a standard uncertainty for the fit to their model "data" of $0.08 \mathrm{mg} \mathrm{kg}^{-1}$ over the oceanic range of parameters if all quantities on the right side are known precisely. Similar formulas are also given for conversion to the other salinity variables discussed above. In particular, the difference between Density Salinity and Preformed Salinity can be determined using

$$
\begin{aligned}
& \delta S_{*}^{\text {dens }} /\left(\mathrm{mgkg}^{-1}\right)=73.7 \Delta \mathrm{TA}+11.8 \Delta \mathrm{DIC} \\
& +81.9 \Delta\left[\mathrm{NO}_{3}^{-}\right]+50.6 \Delta\left[\mathrm{Si}(\mathrm{OH})_{4}\right]\left(\mathrm{mmolkg}^{-1}\right)
\end{aligned}
$$

with a standard uncertainty for the fit to their model "data" of only about $0.01 \mathrm{mg} \mathrm{kg}^{-1}$. The uncertainty is substantially smaller than for Eq. (9) due to the fact that conductivity results are not involved in the determination of Eq. (10). This equation is ideally suited for use in coupled biophysical models in which one wishes to account for the influence of composition anomalies of biological origin on the density and hence on the ocean circulation.

The fact that Density Salinity ensures an accurate estimate for density is particularly useful for physical oceanographic applications since the density and quantities such as compressibility, thermal expansion and haline contraction that 
are derived directly from it are the most crucial properties to determine accurately. Indeed, the salinity argument for the Gibbs function must return accurate results for density to be useful in many oceanographic applications. Our definition of Density Salinity guarantees its utility for the most demanding oceanographic applications even in the presence of significant composition anomalies. Its usage in numerical ocean circulation models is considered next.

\section{The representation of salinity in numerical models}

Any attempt to include the influence of composition anomalies on salinity estimates naturally raises questions about how salinity should be treated in numerical models. Here, we consider a general approach to allow for the effects of non-conservative biogeochemical source terms. To achieve this, Density Salinity $S_{\mathrm{A}}^{\text {dens }}$ is used as the argument of the Gibbs function or the equivalent "equation of state" used in the model to determine density. In the first case considered, Density Salinity is represented as the sum of Preformed Salinity determined by the model conservation equation plus an anomaly representing the effects of non-conservative biogeochemical processes, which are empirically accounted for. Simplifications of this approach are then considered followed by a discussion of a less empirical route forward using biogeochemical models to determine the anomalies.

An ocean model needs to calculate salinity at every time step as a necessary prelude to using the equation of state to determine $\rho$ and its derivatives (for use in the hydrostatic relationship and frequently in neutral mixing algorithms). The current practice in numerical models is to treat salinity as a perfectly conservative quantity in the interior of the ocean. It changes at the surface and at coastal boundaries due to evaporation, precipitation, brine rejection, ice melt and river runoff and satisfies an advection-diffusion equation away from these boundaries. The inclusion of composition anomalies requires changes in this approach for several reasons, the relative importance of which vary in space and time and are not yet fully understood. The changes can be divided into two broad categories. First, in addition to fresh water inputs and brine rejection, all sources and sinks of dissolved material entering or exiting through coastal boundaries, the surface or the sea floor (e.g., the sediment, hydrothermal vents, benthic populations) should be considered as possible sources of composition anomalies. Second, within the interior of the model, changes due to the growth, decay and remineralization of biological material must be considered. We begin by outlining an approach that could take advantage of currently available information to gain insight into how important the presence of composition anomalies might be.

The notion of Preformed Salinity, $S_{*}$, introduced in Sect. 3.1, is useful in considering how to account for composition anomalies in ocean models. The basic idea is that the dissolved material in the ocean can be separated into a salinity component $S_{*}$ that is conservative (just like we have as- sumed for decades for the total salinity variable in numerical models) plus anomalies from this form, $\delta S_{*}^{\text {dens }}=S_{\mathrm{A}}^{\text {dens }}-S_{*}$. These anomalies are caused primarily by biogeochemical processes but may also be locally influenced by surface and coastal boundary inputs (e.g., Millero, 2000b; Feistel et al., 2010b).

Since $S_{*}$ is a conservative variable, given initial values and appropriate boundary conditions, it evolves according to the equation

$$
\frac{\mathrm{d}}{\mathrm{d} t} S_{*}=\nabla \cdot\left(K, D ; S_{*}\right)
$$

where the left-hand side is the material derivative following the appropriately averaged residual-mean velocity (see, for example, IOC et al., 2010 and Griffies, 2004) and the righthand side is a schematic shorthand for the turbulent diffusion of the conservative quantity $S_{*}$ by isopycnal mixing with turbulent diffusivity $K$ and by small-scale vertical mixing with turbulent diffusivity $D$.

Currently, we do not know how to reliably model the nonconservative contribution $\delta S_{*}^{\text {dens }}=S_{\mathrm{A}}^{\text {dens }}-S_{*}$ so we insist that it remains consistent with observational estimates. One possibility is then to determine global observational estimates of $\delta S_{*}^{\text {dens }}(x, y, p)$ and simply add this to the model variable $S_{*}$ to complete the determination of $S_{\mathrm{A}}^{\text {dens }}$. However, experience has shown that even a smooth field of density errors can result in significant anomalies in diagnostic model calculations, primarily due to unrealistic misalignments between the model density field and the model bottom topography. Indeed, even if the correct mean density could somehow be determined, approximations associated with the specification of the model bottom topography can result in significant errors in bottom pressure torques that can degrade the model solution. One way to minimize such errors is to allow some dynamical adjustment of the specified density field so that, for example, density contours tend to align with bottom depth contours where the flow is constrained to follow bottom topography. This simple idea is the key to the success of the robust diagnostic approach (Sarmiento and Bryan, 1982). To allow dynamical adjustment of the salinity anomaly field while still constraining it to be near to the observational estimate $\delta S_{*}^{\text {dens }}(\mathrm{obs})$, we recommend carrying an evolution equation for $\delta S_{*}^{\text {dens }}$ that includes advection and diffusion exactly the same as for $S_{*}$ plus an additional restoring term towards observational estimates that is intended to represent unknown (or poorly known) sources and sinks:

$$
\frac{\mathrm{d}}{\mathrm{d} t} \delta S_{*}^{\mathrm{dens}}=\nabla \cdot\left(K, D ; \delta S_{*}^{\mathrm{dens}}\right)+\frac{1}{\tau}\left(\delta S_{*}^{\mathrm{dens}}(\mathrm{obs})-\delta S_{*}^{\mathrm{dens}}\right),
$$

where $\tau$ is a restoring time. The Density Salinity $S_{\mathrm{A}}^{\text {dens }}$ that is needed for the equation of state in the model is then computed using

$S_{\mathrm{A}}^{\text {dens }}=S_{*}+\delta S_{*}^{\text {dens }}$.

Equations (11) and (12) are our basic equations for the determination of salinity variations. To apply this approach, it 
remains to determine credible observational estimates for $S_{*}$ and $\delta S_{*}^{\text {dens }}$, specify appropriate initial and boundary values and provide a value for the restoring time.

A variety of different approximations that can be used to represent $S_{*}$ and $\delta S_{*}^{\text {dens }}$ in ocean models are discussed in IOC et al. (2010). Here we consider a range of possibilities that includes the most complete and the simplest approaches envisioned. Note that coupling to, for example, a sea ice model that also uses a salinity variable may involve further technical details, but since the sensitivity of the circulation to the small variations we are considering here is largest in the deep ocean we shall not consider these details in our discussion.

Approach (i): $S_{*}$ and $\delta S_{*}^{\text {dens }}$ consistent with Pawlowicz et al. (2010) and McDougall et al. (2009).

In this case, we make use of the full Eqs. (11) through (13). From the results of Pawlowicz et al. (2010) summarized in Table $1 \mathrm{~b}$, we know that the simple estimate $S_{\mathrm{R}}-$ $S_{*} \approx 0.35 \delta S_{\mathrm{R}}^{\mathrm{dens}}$ models the results of more detailed calculations to within an acceptable error. Hence a global observational estimate of $S_{*}$ can be determined from an available $S_{\mathrm{P}}$ climatology (to determine $S_{\mathrm{R}}$ ) and the global observational estimates of $\delta S_{\mathrm{R}}^{\text {dens }}$ provided by McDougall et al. (2009). To obtain an observational estimate of $\delta S_{*}^{\text {dens }}$, we use $\delta S_{*}^{\text {dens }} \approx 1.35 \delta S_{\mathrm{R}}^{\text {dens }}$ (Table $1 \mathrm{~b}$ ) and again use the global estimate of $\delta S_{\mathrm{R}}^{\text {dens }}$ from McDougall et al. (2009). Once the observational estimates are determined, they can be used both as initial conditions for Eqs. (11) and (12) and to specify the deviation from observations that appears in the restoring term in Eq. (12). $S_{*}$ and $\delta S_{*}^{\text {dens }}$ are updated using Eqs. (11) and (12) and the absolute salinity is calculated using Eq. (13) which is then used in the equation of state to determine density and any other thermodynamic properties used in the model.

To complete our system, we must specify the restoring time that appears in Eq. (12). Determination of a "best choice" will require experimentation but an appropriate value is likely in the range of one month to a few years. The lower bound is based on a very rough estimate of the time required for the density field to align with local topography through advective processes. The upper bound is set by the requirement to have the restoring time relatively short compared to vertical and basin-scale horizontal redistribution times.

Finally, we note that the nudging term $\tau^{-1}\left(\delta S_{*}^{\text {dens }}(\mathrm{obs})-\right.$ $\left.\delta S_{*}^{\text {dens }}\right)$ in Eq. (12) is a rather crude representation of the influences of many complicated and poorly understood biogeochemical processes. If inclusion of composition anomalies turns out to have significant consequences, then biogeochemical models will be required to properly model the interior sources and sinks that are believed to dominate the occurrence of composition anomalies in seawater. In this case, Eq. (10) will be very useful. If a biogeochemical model produces estimates of the quantities on the right hand side of this equation, it can be immediately integrated into an ocean model to diagnose the effects of the included biogeochemical processes on the model's density and its circulation.

Approach (ii): Treat salinity as a conservative variable.

It is convenient at this point to add Eqs. (11) and (12) and use Eq. (13) to obtain

$$
\frac{\mathrm{d}}{\mathrm{d} t} S_{\mathrm{A}}^{\mathrm{dens}}=\nabla \cdot\left(K, D ; S_{\mathrm{A}}^{\mathrm{dens}}\right)+\frac{1}{\tau}\left(\delta S_{*}^{\mathrm{dens}}(\mathrm{obs})-\delta S_{*}^{\mathrm{dens}}\right) .
$$

Implementation of Eqs. (12-14) is clearly equivalent to approach (i), with $S_{\mathrm{A}}^{\text {dens }}$ now given by Eq. (14) and $S_{*}$ determined by Eq. (13). There is no computational advantage to implementing Eq. (14) rather than Eq. (11); Eq. (14) merely provides a single equation for the Density Salinity.

An obvious simplification of Eq. (14) is to neglect the restoring term on the right hand side. Under this approximation, Eq. (14) reduces to

$$
\frac{\mathrm{d}}{\mathrm{d} t} S=\nabla \cdot(K, D ; S),
$$

where the variable $S$ has been used to represent the resulting approximation for Absolute Salinity. Use of Eq. (15) will save the computational expense of carrying Eq. (12) since it is no longer required to determine the evolution of the model salinity, but it must be emphasized that $S$ will not provide the best available estimate for $S_{\mathrm{A}}^{\text {dens }}$. Under this approximation, the model's salinity variable is represented as a conservative quantity, which is consistent with the approach used for the past few decades to represent salinity in numerical models. However the influences of biogeochemical processes that result in composition anomalies are ignored.

It remains to specify initial and boundary conditions to complete the estimation of salinity under the approximation (15). Three sub-cases are of interest which we refer to as options (ii-a), (ii-b) and (ii-c). Option (ii-a) explicitly allows for the influence of composition anomalies in the specification of initial and boundary conditions, option (ii-b) allows for composition anomalies only to the extent that they are captured by conductivity measurements and option (iic) explicitly removes the influence of composition anomalies from the specification of initial and boundary conditions.

Option (ii-a): In this case, initial and boundary conditions are specified consistent with observational estimates of Density Salinity $S_{\mathrm{A}}^{\text {dens }}$. The model is initialized with the best available climatological estimate of $S_{\mathrm{A}}^{\text {dens }}$ which would currently be determined from a climatological estimate of $S_{\mathrm{R}}$ $\left(=(35.16504 / 35) S_{\mathrm{P}} \mathrm{g} \mathrm{kg}^{-1}\right)$ plus the correction term $\delta S_{\mathrm{R}}^{\text {dens }}$ obtained from the McDougall et al. (2009) global atlas. Specification of the fluxes of water across the model boundaries then completes the system. If restoring boundary conditions are desirable, then $S$ is restored to observational estimates of $S_{\mathrm{A}}^{\mathrm{dens}}$. Using this approach, the equation of state in the model receives the correct salinity argument initially, but over some longer time scale determined by circulation 
and mixing processes, the absence of the non-conservative source terms (the last term in Eq. 14) will reduce the fidelity of the solution; the model salinity will degrade as an estimate of Density Salinity and the representation of density will degrade as a result. An advantage of this approach is that it initially takes into account the influence of the spatial variations in seawater composition, but the fidelity of the solution will inevitably degrade over time due to the omission of nonconservation effects from the right hand side of Eq. (15).

Option (ii-b): This option is considered as a close approximation to past (and current) practice. The model salinity is initialized with a climatological estimate of $S_{\mathrm{R}}$ (the best approximation for $S_{\mathrm{A}}^{\text {dens }}$ that doesn't explicitly account for composition anomalies) and the fluxes of water are specified across the boundaries of the model. If restoring boundary conditions are desirable, then $S$ would be restored to observational estimates of Reference Salinity. If the resulting salinity estimates are then substituted into the TEOS-10 equation for density, results will be very similar to those obtained with the current practice of initializing a model with a climatological estimate of $S_{\mathrm{P}}$, specifying water fluxes across the boundaries or restoring to observational estimates of Practical Salinity to determine the evolution of the model salinity and then using EOS-80 to determine density.

Option (ii-c): A third option is to acknowledge that Eq. (15) is really only appropriate in the absence of the biogeochemical processes that result in composition anomalies. Since this is only correct for Preformed Salinity, it is consistent to initialize the model with a climatological estimate of $S_{*}$ and either specify fluxes of water across the model boundaries or restore surface values to observational estimates of $S_{*}$. TEOS-10 would then be used to estimate density based on the resulting salinity estimates. The results of this case are of interest since comparison with those obtained using option (i) discussed above would provide a direct estimate the influences of biogeochemical processes on the large scale deep ocean circulation. In particular, one could compare robust diagnostic results obtained with option (ii-c) to the corresponding results obtained with approach (i) to determine a reasonable estimate of the influence of composition anomalies on the large scale ocean circulation without requiring major computations.

An immediate indication of the errors associated with using either approach (ii-b) or (ii-c) rather than approach (i) is provided by Fig. 2. Similar errors will develop over time for approach (ii-a). The vertical axis in this figure is the difference between the northward density gradient at constant pressure when the equation of state is evaluated with observational estimates of $S_{\mathrm{A}}^{\text {dens }}$ and with $S_{\mathrm{R}}$ as the salinity argument. The figure shows that for all the data in the world ocean below a depth of $1000 \mathrm{~m}, 60 \%$ of the gradients are in error by more than $2 \%$. If this graph were done with $S_{*}$ rather than $S_{\mathrm{R}}$ as the reference with which results are compared then the error would be increased by the factor 1.35 .

While the differences shown in Fig. 2 are not large, they

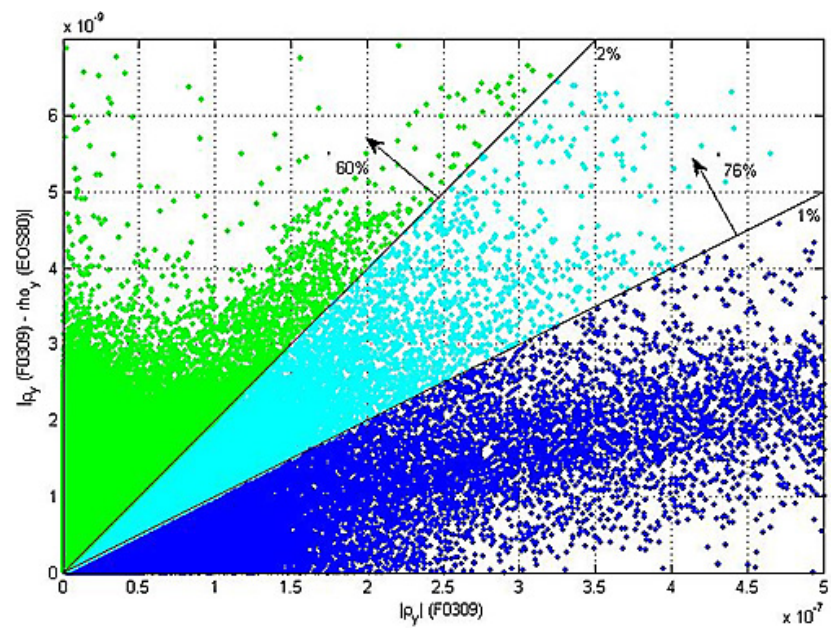

Fig. 2. The northward density gradient at constant pressure (the horizontal axis) for all the data in the ocean atlas of Gouretski and Koltermann (2004) for $p>1000$ dbar. The vertical axis is the magnitude of the difference between evaluating the density gradient using $S_{\mathrm{A}}^{\mathrm{dens}}$ as the salinity argument in the TEOS-10 expression for density compared with using $S_{\mathrm{P}}$ in the EOS-80 algorithm for density. The latter corresponds to current practice and for the purpose of this figure is not significantly different from using $S_{\mathrm{R}}$ in TEOS-10.

are also not insignificant. Noting that the geostrophic transport associated with a vertically uniform horizontal density difference of $\delta \rho$ across a box of arbitrary width $L$ and thickness $H$ is approximately $g \delta \rho H^{2} /(2 \rho f)$, it is easily seen that a density change of just $10 \mathrm{~g} / \mathrm{m}^{3}$ over a depth of $1000 \mathrm{~m}$ is associated with a $0.5 \mathrm{~Sv}$ change in volume transport through the section, which is not entirely negligible. We also note that the systematic density gradient anomalies in the north-south direction are likely to result in robust changes in the bottom pressure torque with a potentially more significant effect on the circulation. Investigation of the resulting changes is certainly warranted.

Obviously, each of the approaches discussed above represents a rather crude method to include the effects of composition anomalies on the results of ocean circulation models. Nevertheless, we suggest that examination of such simplified formulations will provide useful new insights with minimal effort. We therefore believe that the systematic examination of approaches (i) and (ii) and comparison of the results will represent a useful starting point for the examination of the effects of composition anomalies.

\section{Summary and conclusions}

Both the Reference Composition (RC) and the ReferenceComposition Salinity Scale (RCSS) have been defined precisely and we recommend that they remain unchanged in the future to provide stable benchmarks for the composition of 
Standard Seawater and a stable scale for the presentation of salinity results.

The RC was defined by Millero et al. (2008a) as a "best estimate" of the composition of SSW that was analyzed during the mid-1970s and RCSW is seawater with the RC. The RCSS was defined to provide a best estimate of the mass fraction of dissolved material in RCSW and the SSW that it approximates. The use of RCSW as an approximation for SSW improves our numerical estimates of its absolute salinity by about $0.165 \mathrm{~g} \mathrm{~kg}^{-1}$ in water with a Practical Salinity of 35 . Nevertheless, uncertainties remain. Subsequent investigations (Pawlowicz, 2009; Lee et al., 2010) have already identified smaller but quantifiable differences between RCSW and SSW, and given the current limitations of our knowledge of the true composition of seawater, it is likely that future investigations will show even more changes. It might be tempting to modify the definition of the RC and also the RCSS to continue to provide a best estimate for the composition and absolute salinity of SSW in the future. However, such adjustments would inevitably cause confusion and could result in problems detecting long-term changes in ocean salinity and in providing reliable estimates of the thermodynamic properties of seawater. We therefore recommend that both the RC and the RCSS remain unchanged. If improved estimates of the mass fraction of SSW are available and situations arise in which it is desirable to have more precise estimates of the mass fraction, corrected values can be determined for special-purpose applications. Such corrections would be easily achieved since the RCSS has been defined so that the Absolute Salinity of SSW on this scale can differ from the true mass fraction only by a fixed proportionality constant.

The next largest uncertainty in our ability to predict the properties of seawater arises from spatial (and temporal) variations in the composition of seawater. These give rise to salinity variations of up to $0.03 \mathrm{~g} \mathrm{~kg}^{-1}$ in the open ocean and may exceed $0.1 \mathrm{~g} \mathrm{~kg}^{-1}$ in coastal waters or estuaries. In order to correctly understand these effects a number of different salinity variables are defined, each of which is useful in different applications. The term Solution Salinity is introduced for the mass fraction of dissolved material after it is in solution and in thermodynamic equilibrium. This is also the most "intuitive" definition of absolute salinity. The name Solution Salinity emphasizes that the mass fraction is determined for the dissolved material actually in solution, accounting for the fact that chemical reactions that occur when material is added can convert $\mathrm{H}_{2} \mathrm{O}$ to (or from) chemical forms defined to be part of the "solute". The term Added-Mass Salinity is used to refer to the mass fraction based on the mass of solute added to SSW before entering solution. The Density Salinity is the Solution Salinity of SSW that has the measured density of our anomalous seawater. This is not the same as the actual Solution Salinity when the relative composition differs from that of SSW, but it is a measureable and SI-traceable quantity that is probably of most relevance to dynamical in- vestigations as it allows for the correct calculation of density when used as an argument in the TEOS-10 Gibbs function. When considering seawater that includes anomalies, MFWM used the term Absolute Salinity to refer to Density Salinity and we continue this practice with the recognition that Density Salinity may deviate significantly from Solution Salinity when composition anomalies are present.

We emphasize that our choice of salinity argument for use in the Gibbs function is the Density Salinity which is defined such that it will provide the most accurate results possible for density even though it may not provide equally accurate results for the mass fraction of dissolved material. The inclusion of composition anomalies necessarily introduces some inconsistencies between these two quantities. Our choice ensures that density and related quantities, as well as Conservative Temperature ("heat content" per unit mass) are accurately represented by the Gibbs function. Consequently, we believe that our choice for the representation of salinity is the most relevant generalization to allow for composition anomalies. To improve on this measure of salinity, it seems likely that an additional parameter (or parameters) representing the effects of composition anomalies would be required as an input to the Gibbs function. Such an extension has been implemented for the Baltic Sea (Feistel et al., 2010b) and it may be useful in the future to develop a similar extension for the open ocean.

There are currently three methods available to estimate the Density Salinity for use as an argument of the Gibbs function. If only measurements of Practical Salinity and geographic sampling position are available, then Density Salinity can be estimated using the Reference Salinity determined from Eq. (8) plus the salinity anomaly $\delta S_{\mathrm{R}}^{\text {dens }}$ or $\delta S_{\mathrm{A}}$ determined from a lookup table (McDougall et al., 2009). If on the other hand, one measures density in the lab at known values of temperature and pressure, ideally at the reference conditions of $25^{\circ} \mathrm{C}$ and $101325 \mathrm{~Pa}$, then a direct estimate of Density Salinity is available through the solution of Eq. (5). If the Practical Salinity is also measured, then an independent estimate of $\delta S_{\mathrm{R}}^{\text {dens }}$ is available which can be used to improve the reliability of the lookup table. Finally, relationships like Eq. (9) have been proposed (Brewer and Bradshaw, 1975; Millero, 2000a; Millero et al., 2008b, 2009; Pawlowicz et al., 2010) to estimate the density anomaly from direct measurements of some or all of the nonconservative parameters in seawater. Collection of information to verify all of these approaches is particularly important for semi-enclosed basins where current estimates of $\delta S_{\mathrm{R}}^{\text {dens }}$ are most uncertain.

Note that although the formal definition of Absolute Salinity as the Density Salinity of seawater can be extended to near-coastal waters without difficulty, a variety of operational and conceptual issues arise in these situations that increase the complications relative to the open-ocean cases discussed here. An example of a conceptual issue is that the correct definition of Preformed Salinity is less obvious. Although the chemical composition in coastal waters differs 
from that of SSW, some of these anomalies occur because of boundary (i.e. riverine) inputs of dissolved material and not through nonconservative biogeochemical processes. Preformed Salinity could represent either the SSW portion of the coastal water, or the larger portion that includes the conservative part of these composition anomalies, added in a manner that dilutes their effect as salinities approach open-ocean values. In addition, composition anomalies in coastal areas are in general poorly known, and may change over relatively short periods of time. Thus, numerical conversion factors valid at one particular time and place may not be appropriate at other times. This raises obvious problems in the correct presentation of time series and/or transects that begin near the coast and end well offshore. On the other hand, in these regions the density anomalies themselves are generally unimportant in practical terms relative to the much larger density gradients present. A full discussion of the application of the Gibbs function in near-coastal waters is beyond the scope of this paper, but will be addressed in future work.

We have stressed that the most appropriate input to the Gibbs function for most dynamical physical oceanographic applications is Density Salinity. Nevertheless, use of Reference Salinity will be more appropriate in some applications where maximum simplicity is desirable and reduced accuracy is acceptable as well as for studies such as the detection of salinity variations associated with climate change where precision may be more critical than accuracy. Regarding the latter point, we note that the reproducibility of Reference Salinity is roughly $0.002 \mathrm{~g} \mathrm{~kg}^{-1}$ and is not subject to future changes provided the RCSS is not altered. On the other hand, the uncertainties in estimates of Density Salinity are several times larger in some situations. At present, the most well tested way to determine the influence of composition anomalies on global estimates of density salinity involves use of a lookup table that is based on a spatially varying correlation between Density Salinity anomalies and silicate anomalies estimated using less than a thousand individual measurements from just 105 locations. As the number and distribution of the measurements available to determine the global variation of the composition anomalies improves, this lookup table will be refined and changes of order $0.01 \mathrm{~g} \mathrm{~kg}^{-1}$ are likely to occur in some regions where the current data coverage is sparse and of order $0.003 \mathrm{~g} \mathrm{~kg}^{-1}$ more generally throughout the ocean. Further, use of relations such as Eqs. (9) and (10) will be desirable in some cases and these might also change estimates by similar amounts in some regions. It is therefore anticipated that methodological changes will result in changes in Density Salinity estimates that may be substantially larger than the precision with which we can determine Reference Salinity. Consequently, Reference Salinity should be used in applications where precision is more critical than accuracy, but we recommend that Density Salinity be used whenever the highest available accuracy is required for density.
The inclusion of the effects of composition anomalies on density and other thermodynamic properties of seawater represents a new and challenging area of research. We have discussed one approach to evaluating the potential significance of these effects through the use of numerical models. Initially we propose an empirical approach that can be used to provide new insights into the significance of this effect. If the effects prove to be significant, then more sophisticated models that account for variable inputs through surface and coastal boundaries as well as chemical and biological processes will be required.

\section{Appendix A}

\section{Nomenclature}

This appendix provides a reference for the definitions of various forms of salinity and density variables used here and the relations between them. The notation used is a consistent simplification of that used in Pawlowicz et al. (2010). The basic symbols used are summarized in Table A1 and the relations between them are illustrated in Fig. A1.

The notation is chosen to maintain consistency with previous usage but extended to deal with composition anomalies in a manner that is intended to be intuitively obvious. We retain the symbols $S_{\mathrm{P}}$ and $S_{\mathrm{R}}$ for the commonly used Practical Salinity variable and the Reference Salinity variable introduced by MFWM. An additional symbol of this style $S_{*}$ is used to represent Preformed Salinity which is introduced as a conservative parameter to which anomalies, primarily of biochemical origin, are added. In previous publications, the symbol $S_{\mathrm{A}}$ and term Absolute Salinity has been used to represent the mass fraction of dissolved material in seawater (here defined as the Solution Salinity). In practice however, Absolute Salinity was approximated by the Density Salinity. With the addition of composition anomalies, distinctions arise between quantities that were previously treated as equivalent, and so new variable names are required to distinguish them. In particular, based on the work of Pawlowicz, et al. (2010), we now know that the Density Salinity anomalies do not provide a good approximation for the anomalies in the mass fraction of dissolved material in seawater. To make the distinction between these different forms of salinity while maintaining a connection with previous usage, we represent the Density Salinity and the Solution Salinity (i.e., the mass fraction of dissolved material in solution) by the symbols $S_{\mathrm{A}}^{\text {dens }}$ and $S_{\mathrm{A}}^{\text {soln }}$. In addition, Added-Mass Salinity, denoted by $S_{\mathrm{A}}^{\text {add }}$, represents the form of salinity obtained when the mass of anomalous solute is determined prior to adding it to solution rather than after its dissolution and equilibration at reference values of temperature, pressure and concentration. When $S_{\mathrm{A}}$ is used without a superscript, it will be taken to refer to Density Salinity, consistent with the assignment made in practice in most previous studies and justified in this paper. 


\section{a) SSW}

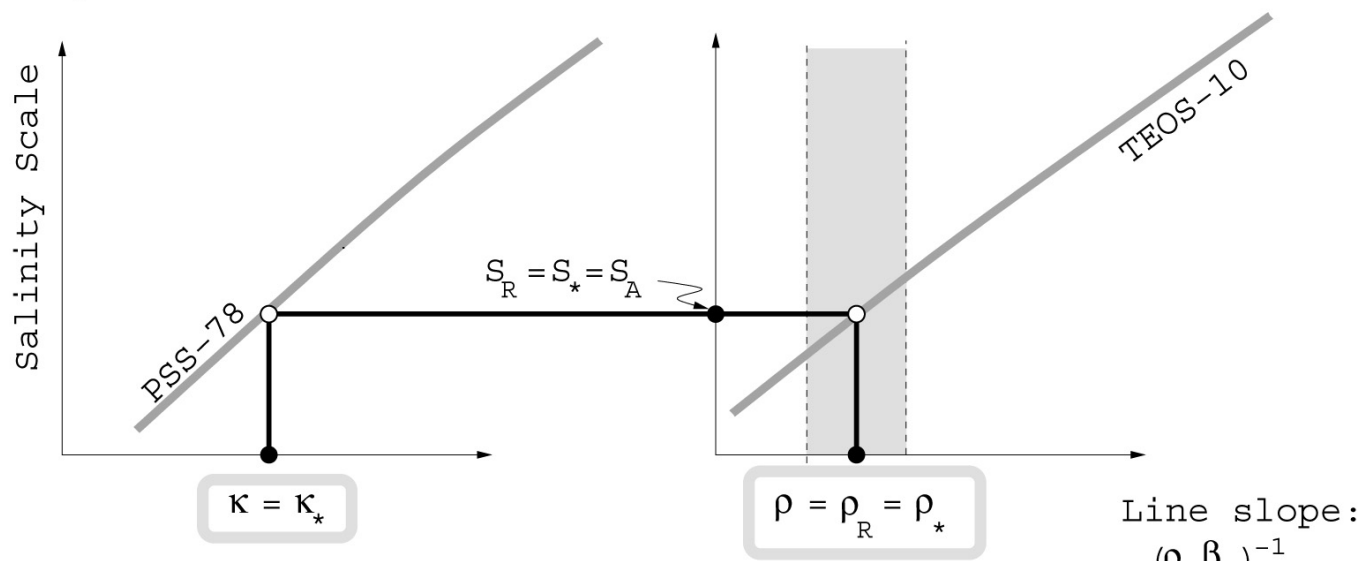

b) Arbitrary seawater

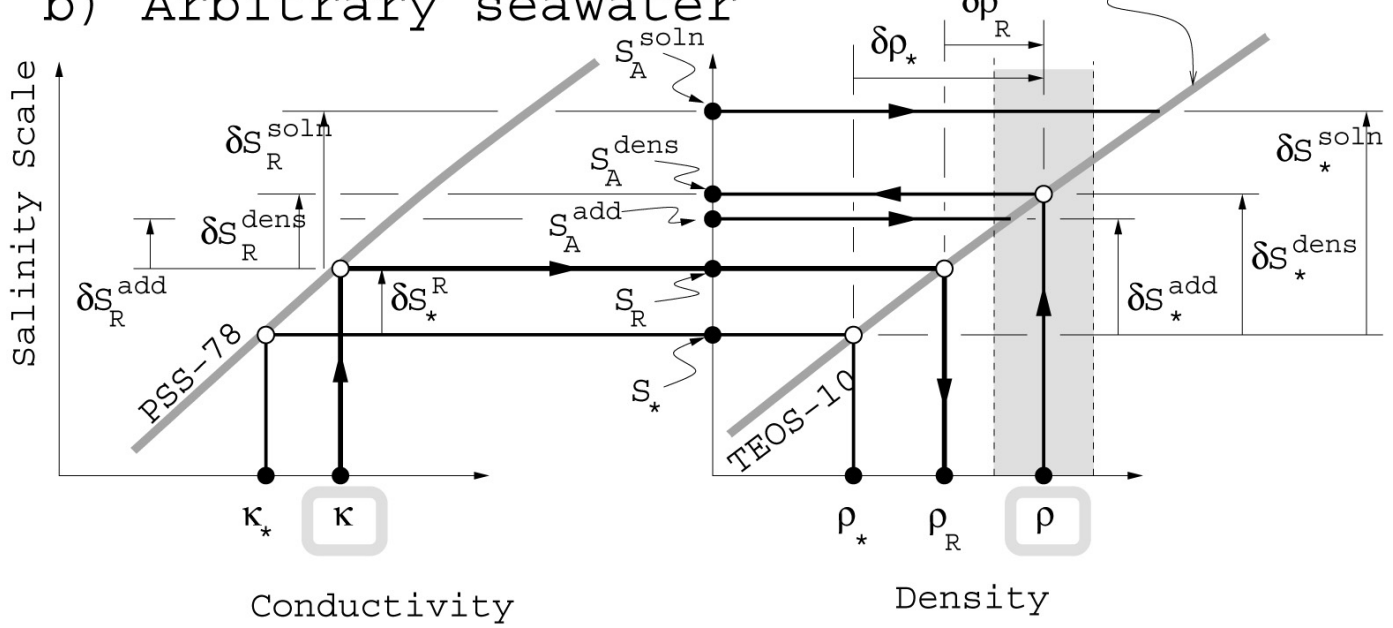

Fig. A1. This figure schematically shows the relationships between different variables used to characterize seawater. (a) For SSW. The estimate $S_{\mathrm{R}}$ of the Absolute Salinity $S_{\mathrm{A}}$ is used to define a conductivity/salinity relationship (schematically shown as the scaled PSS-78 curve on the left hand graph), and a density/salinity relationship (schematically shown as the TEOS-10 curve on the right hand graph). The vertical gray bar indicates the uncertainty range of measured densities around the TEOS-10 prediction. (b) For arbitrary seawater, composed of a preformed SSW component with absolute salinity $S_{*}$, plus a composition anomaly. Observed values are indicated by labels outlined in gray along the horizontal axes. The observed conductivity $\kappa$ is related to a Reference Salinity $S_{\mathrm{R}}$ and a reference density $\rho_{\mathrm{R}}$ using relationships developed for SSW. However, the observed density $\rho$ is related to the Density Salinity $S_{\mathrm{A}}^{\text {dens }} \neq S_{\mathrm{R}}$. Estimates of mass fraction salinities $S_{\mathrm{A}}^{\text {add }}$ and $S_{\mathrm{A}}^{\text {soln }}$ directly determined from the full chemical composition are respectively defined based on whether the mass of anomalous solutes are accounted for before or after their addition to the Preformed Salinity. The difference between the two estimates reflects the effects of equilibrium chemistry within seawater, which converts some $\mathrm{H}_{2} \mathrm{O}$ into the chemical forms comprising the solute. Empirically, the relationship in the ocean between $S_{\mathrm{A}}^{\text {add }}$ and measured densities $\rho$ can be described, within typical observational error, by TEOS-10. This is not true in general for the relationship between $S_{\mathrm{A}}^{\text {soln }}$ and $\rho$. 
Table A1. The various salinity variables and the relations between them.

\begin{tabular}{|c|c|c|c|}
\hline Quantity & Symbols & Equations & Comments \\
\hline Practical Salinity & $S_{\mathrm{P}}$ & PSS-78 & Unitless conductivity-based salinity \\
\hline Reference Salinity & $S_{\mathrm{R}}$ & $(35.16504 / 35) S_{\mathrm{P}} \mathrm{g} / \mathrm{kg}$ & $\begin{array}{l}\text { Absolute Salinity of RCSW. For a general seawater } \\
\text { parcel, } S_{\mathrm{R}} \text { is influenced by } \mathrm{H}_{2} \mathrm{O} \text { exchange and } \\
\text { conductive anomalies }\end{array}$ \\
\hline Preformed Salinity & $S_{*}$ & $S_{\mathrm{R}}-\delta S_{*}^{\mathrm{R}}$ & $\begin{array}{l}\text { Standard Seawater to which anomalies are added; } \\
\text { influenced by } \mathrm{H}_{2} \mathrm{O} \text { exchange. } S_{*} \text { can be calculated } \\
\text { from other salinity measures by subtracting off the } \\
\text { effect of composition anomalies. }\end{array}$ \\
\hline Density Salinity & $S_{\mathrm{A}}^{\text {dens }}\left(S_{\mathrm{A}}\right)$ & $S_{\mathrm{R}}+\delta S_{\mathrm{R}}^{\text {dens }}, S_{*}+\delta S_{*}^{\text {dens }}$ & Provides the best estimate of density using TEOS- 10 . \\
\hline Solution Salinity & $S_{\mathrm{A}}^{\text {soln }}$ & $S_{\mathrm{R}}+\delta S_{\mathrm{R}}^{\text {soln }}, S_{*}+\delta S_{*}^{\text {soln }}$ & $\begin{array}{l}\text { mass fraction of material actually dissolved in } \\
\text { solution, as in MFWM }\end{array}$ \\
\hline Added-Mass Salinity & $S_{\mathrm{A}}^{\mathrm{add}}$ & $S_{\mathrm{R}}+\delta S_{\mathrm{R}}^{\text {add }}, S_{*}+\delta S_{*}^{\text {add }}$ & Salinity measure used in lab analyses \\
\hline Preformed - Reference & $\delta S_{\mathrm{R}}^{*}$ & $S_{*}-S_{\mathrm{R}}$ & \multirow{4}{*}{$\begin{array}{l}\text { Additions used to adjust from Reference Salinity } \\
\text { to the other salinity parameters }\end{array}$} \\
\hline Density - Reference & $\delta S_{\mathrm{R}}^{\text {dens }}\left(\delta S_{\mathrm{A}}\right)$ & $S_{\mathrm{A}}^{\mathrm{dens}}-S_{\mathrm{R}}$ & \\
\hline Solution - Reference & $\delta S_{\mathrm{R}}^{\mathrm{soln}}$ & $S_{\mathrm{A}}^{\text {soln }}-S_{\mathrm{R}}$ & \\
\hline Added-mass - Reference & $\delta S_{\mathrm{R}}^{\mathrm{add}}$ & $S_{\mathrm{A}}^{\mathrm{add}}-S_{\mathrm{R}}$ & \\
\hline Reference - Preformed & $\delta S_{*}^{\mathrm{R}}$ & $S_{\mathrm{R}}-S_{*}$ & \multirow{4}{*}{$\begin{array}{l}\text { Additions used to adjust from Preformed Salinity } \\
\text { to the other salinity parameters }\end{array}$} \\
\hline Density - Preformed & $\delta S_{*}^{\text {dens }}$ & $S_{\mathrm{A}}^{\mathrm{dens}}-S_{*}$ & \\
\hline Solution - Preformed & $\delta S_{*}^{\text {soln }}$ & $S_{\mathrm{A}}^{\mathrm{soln}}-S_{*}$ & \\
\hline Added-mass - Preformed & $\delta S_{*}^{\text {add }}$ & $S_{\mathrm{A}}^{\mathrm{add}}-S_{*}$ & \\
\hline Haline contraction coefficient for RCSW & $\beta_{\mathrm{R}}$ & $\frac{1}{\rho_{\mathrm{R}}} \frac{\partial \rho}{\partial S_{\mathrm{R}}}$ & $\begin{array}{l}\text { Calculated from the TEOS-10 } \\
\text { Gibbs function }\end{array}$ \\
\hline
\end{tabular}

The special case of Standard Seawater is particularly simple as illustrated in the upper panel of Fig. A1. In this case, the Reference Salinity, Density Salinity, Solution Salinity, Added-Mass Salinity and Preformed Salinity are all equivalent to within measurement uncertainties and they can be unambiguously determined simply by measuring conductivity. An optimal estimate of the true density is then determined using any of these salinity variables as an input to the equation of state. In this case, the Practical Salinity is (35/35.16504) times any of the other salinity variables when they are expressed in $\mathrm{g} \mathrm{kg}^{-1}$ (e.g. $S_{\mathrm{P}} \approx(35 / 35.16504) \times S_{\mathrm{A}} /(\mathrm{g} / \mathrm{kg})$ for SSW).

In studies involving composition anomalies, each of the different salinity variables is distinct and it is convenient to consider them in terms of base quantities and anomalies from these base quantities. For situations in which the Reference Salinity is known and an improved estimate of one of the other salinity variables is required, the base quantity is chosen as the Reference Salinity $S_{\mathrm{R}}$ or the density $\rho_{\mathrm{R}}$ determined from the SSW Gibbs function using the Reference Salinity as an input. When considering the effects of composition anomalies of biogeochemical origin (or in discussion of laboratory studies) it is more convenient to use the "preformed" quantities $S_{*}$ and $\rho_{*}$ as base quantities.
Increments relative to either Reference or Preformed values all begin with the symbol $\delta$. The increment relative to Reference values is $\delta \rho_{\mathrm{R}}=\rho-\rho_{\mathrm{R}}$ where the true density is indicated by $\rho$. If the density increment relative to the preformed density is required, it should be represented by $\delta \rho_{*}=\rho-\rho_{*}$.

For salinity, the increments begin at either the Reference or Preformed base values and end at any of the five possibilities Reference (R), Preformed (*), Density (dens), Solution (soln) or Added-Mass (add) Salinities. The subscript $\mathrm{R}$ is used to indicate use of the Reference Salinity as the base quantity and subscript $*$ is used to indicate use of Preformed Salinity as the base quantity. The five target values listed above are indicated by $\mathrm{R}, *$, dens, soln and add. Thus for example, $\delta S_{\mathrm{R}}^{*}=S_{*}-S_{\mathrm{R}}, \delta S_{\mathrm{R}}^{\text {dens }}=S_{\mathrm{A}}^{\text {dens }}-S_{\mathrm{R}}$ and $\delta S_{*}^{\text {dens }}=S_{\mathrm{A}}^{\text {dens }}-S_{*}$. 
Table A2. Glossary of abbreviations.

\begin{tabular}{|c|c|}
\hline$C l$ & Chlorinity \\
\hline DIC & Dissolved Inorganic Carbon \\
\hline EOS-80 & Equation Of State defined in 1980 \\
\hline IAPSO & $\begin{array}{l}\text { International Association for the Physical } \\
\text { Sciences of the Oceans }\end{array}$ \\
\hline IAPWS & $\begin{array}{l}\text { International Association for the } \\
\text { Properties of Water and Steam }\end{array}$ \\
\hline IOC & $\begin{array}{l}\text { Intergovernmental } \\
\text { Commision }\end{array}$ \\
\hline IPTS-68 & $\begin{array}{l}\text { International Practical Temperature Scale } \\
\text { defined in } 1968\end{array}$ \\
\hline ITS-90 & International Temperature Scale of 1990 \\
\hline KCl-normalized & $\begin{array}{l}\text { Seawater normalized to a Practical } \\
\text { Salinity of } 35\end{array}$ \\
\hline MFWM & Millero et al. (2008a) \\
\hline PSS-78 & Practical Salinity Scale defined in 1978 \\
\hline $\mathrm{RC}$ & $\begin{array}{l}\text { Reference Composition - the } \\
\text { composition model for Standard } \\
\text { Seawater introduced by MFWM }\end{array}$ \\
\hline RCSS & Reference-Composition Salinity Scale \\
\hline $\begin{array}{l}\text { RCSW } \\
\text { SI }\end{array}$ & $\begin{array}{l}\text { Reference-Composition Seawater } \\
\text { International System of Units }\end{array}$ \\
\hline Son $C l$ & $\begin{array}{l}\text { The ratio of Practical Salinity to } \\
\text { Chlorinity for SSW which is also used as } \\
\text { an approximation for RCSW in (1) }\end{array}$ \\
\hline SSW & IAPSO Standard Seawater \\
\hline SSW76 & $\begin{array}{l}\text { The composition model for SSW } \\
\text { introduced by Pawlowicz (2010) }\end{array}$ \\
\hline TA & Total Alkalinity \\
\hline TEOS-10 & $\begin{array}{l}\text { Thermodynamic Equation of Seawater } \\
2010\end{array}$ \\
\hline UNESCO & $\begin{array}{l}\text { United Nations Educational, Scientific } \\
\text { and Cultural Organization }\end{array}$ \\
\hline VSMOW & Vienna Standard Mean Ocean Water \\
\hline
\end{tabular}

Acknowledgements. We thank Brian King for discussions regarding the potential pitfalls of updating the Reference-Composition Salinity Scale and the international organizations IOC, SCOR and IAPSO for their support of the work done by WG127. DW acknowledges support from the Center for Ocean Model Development for Applications (COMDA), Department of Fisheries and Oceans, Canada.

Edited by: R. Tailleux

\section{References}

Bacon, S., Culkin, F., Higgs, N., and Ridout, P.: IAPSO Standard Seawater: definition of the uncertainty in the calibration procedure, and stability of recent batches, J. Atmos. Ocean. Tech., 24, 1785-1799, 2007.

Brewer, P. G. and Bradshaw, A.: The effect of non-ideal composition of seawater on salinity and density, J. Mar. Res., 33, 157$175,1975$.

Chen, C.-T. A.: Shelf-vs. dissolution-generated alkalinity above the chemical lysocline, Deep-Sea Res. Pt. II, 49, 5365-5375, 2002.

Chen, C. T. and Millero, F. J.: Precise thermodynamical properties for natural waters covering only the limnological range, Limnol. Oceanogr., 31(3), 657-662, 1986.

Culkin, F. and Smith, N.: Determination of the concentration of potassium chloride solution having the same electrical conductivity, at $15^{\circ} \mathrm{C}$ and infinite frequency, as Standard Seawater of salinity $35.0000 \%$ (Chlorinity 19.37394\%o), UNESCO Techn. Pap. Mar. Sci. 37, UNESCO, Paris, 27-28, 1981.

Curry, R., Dickson, B., and Yashayaev, I.: A change in the freshwater balance of the Atlantic Ocean over the past four decades, Nature, 426, 826-829, 2003.

Dauphinee, T. M., Ancsin, J., Klein, H. P., and Phillips, M. J.: The effect of concentration and temperature on the conductivity ratio of potassium chloride solutions to Standard Seawater of salinity 35\%o (Cl 19.3740\%o), UNESCO Techn. Pap. Mar. Sci. 37, UNESCO, Paris, 21-26, 1981 .

Dickson, R., Curry, R., and Yashayaev, I.: Recent changes in the North Atlantic, Philos. T. Roy. Soc. A, 15, 1917-33 (discussion 1933-4), 2003.

Dickson, R. R., Yashayaev, I., Meincke, J., Turrell, W., Dye, S., and Holfort, J.: Rapid freshening of the Deep North Atlantic over the past four decades, Nature, 416, 832-837, 2002.

Feistel, R.: A new extended Gibbs thermodynamic potential of seawater, Progr. Oceanogr., 58, 43-115, 2003.

Feistel, R.: A Gibbs function for seawater thermodynamics for -6 to $80^{\circ} \mathrm{C}$ and salinity up to $120 \mathrm{~g} / \mathrm{kg}$, Deep-Sea Res. Pt. I, 55, 1639-1671, 2008.

Feistel, R.: Extended equation of state for seawater at elevated temperature and salinity, Desalination, 250, 14-18, 2010.

Feistel, R. and Hagen, E.: On the Gibbs thermodynamic potential of seawater, Progr. Oceanogr., 36, 249-327, 1995.

Feistel, R. and Marion, G. M.: A Gibbs-Pitzer function for highsalinity seawater thermodynamics, Progr. Oceanogr., 74, 515539, 2007.

Feistel, R. and Weinreben, S: Is Practical Salinity conservative in the Baltic Sea?, Oceanologia, 50, 73-82, available at: http: //www.iopan.gda.pl/oceanologia/50_1.html\#A6, 2008.

Feistel, R., Weinreben, S., Wolf, H., Seitz, S., Spitzer, P., Adel, B., Nausch, G., Schneider, B., and Wright, D. G.: Density and Absolute Salinity of the Baltic Sea 2006-2009, Ocean Sci., 6, 3-24, doi:10.5194/os-6-3-2010, 2010a.

Feistel, R., Marion, G. M., Pawlowicz, R., and Wright, D. G.: Thermophysical property anomalies of Baltic seawater, Ocean Sci., 6, 949-981, doi:10.5194/os-6-949-2010, 2010b.

Fofonoff, N. P. and Millard, R. C.: Algorithms for the computation of fundamental properties of seawater, UNESCO Techn. Pap. Mar. Sci., 44, 53 pp., 1983.

Griffies, S. M.: Fundamentals of Ocean Climate Models, Princeton, Princeton University Press, NJ, 518 pp., 2004. 
Grosso, P. LeMenn, M., De Bougrenet De La Tocnaye, J.-L., Wu, Z. Y., and Malarde, D.: Practical versus Absolute Salinity measurements: new advances in high performance seawater salinity sensors, Deep-Sea Res. Pt. I, 57, 151-156, 2010.

Hill, K. D., Dauphinee, T. M., and Woods, D. J.: The extension of the Practical Salinity scale 1978 to low salinities, IEEE J. Oceanic Eng., OE-11, 109-112, 1986.

IAPWS: Guideline on the Use of Fundamental Physical Constants and Basic Constants of Water, The International Association for the Properties of Water and Steam, Gaithersburg, Mayland, USA, September 2001, Revision September 2008, available at: http: //www.iapws.org, last access: December 2010.

IAPWS: Release on the Ionization Constant of $\mathrm{H}_{2} \mathrm{O}$, The International Association for the Properties of Water and Steam, Lucerne, Switzerland, August 2007, available at: http://www. iapws.org, last access: December 2010.

IAPWS: Release on the IAPWS Formulation 2008 for the Thermodynamic Properties of Seawater, The International Association for the Properties of Water and Steam, Berlin, Germany, September 2008, available at: http://www.iapws.org, last access: December 2010.

IAPWS: Supplementary Release on a Computationally Efficient Thermodynamic Formulation for Liquid Water for Oceanographic Use, The International Association for the Properties of Water and Steam, Doorwerth, The Netherlands, September 2009, available at: http://www.iapws.org, last access: December 2010.

IOC, SCOR and IAPSO: The International Thermodynamic Equation Of Seawater - 2010: Calculation and Use of Thermodynamic Properties, Intergovernmental Oceanographic Commission, Manuals and Guides No. 56., UNESCO (English), 196 pp., 2010 available at: http://www.TEOS-10.org, last access: December 2010 .

Joyce, T., Pickart, R., and Millard, R.: Long-term hydrographic changes at 52 and $668 \mathrm{~W}$ in the North Atlantic subtropical gyre and Caribbean, Deep-Sea Res. Pt. II, 46, 245-278, 1999.

Kawano, T., Aoyama, M., Joyce, T., Uchida, H., Takatsuki, Y., and Fukasawa, M.: The latest batch-to-batch difference table of Standard Seawater and its application to the WOCE onetime sections, J. Oceanogr., 62, 777-792, 2006.

Kester, D. R, Duedall, I. W., Conners, D., and Pytkowicz, R. M.: Preparation of artificial seawater, Limnol. Oceanogr., 12, 176$179,1967$.

Lee, K., Kim, T.-W., Byrne, R. H., Millero, F. J. Feely, R. A., and Liu, Y.-M.: The universal ratio of boron to Chlorinity for the North Pacific and North Atlantic oceans, Geochim. Cosmochim. Ac., 74, 1801-1811, 2010

Levitus, S.: Interpentadal variability of salinity in the upper $150 \mathrm{~m}$ of the North Atlantic Ocean, 1970-1974 versus 1955-1959, J. Geophys. Res., 94, 9679-9685, 1989.

Lewis, E. L.: The Practical Salinity scale 1978 and its antecedents, UNESCO Techn. Pap. Mar. Sci. 37, UNESCO, Paris, 13-18, 1981.

Lewis, E. and Wallace, D. W. R.: Program developed for $\mathrm{CO}_{2}$ system calculations, ORNL/CDIAC-105, Oak Ridge National Laboratory, 1998.

Marion, G. M. and Kargel, J. S.: Cold Aqueous Planetary Geochemistry with FREZCHEM: From Modeling to the Search for Life at the Limits, Springer, Berlin/Heidelberg, 2008.

Marion, G. M., Kargel, J. S., Catling, D. C., and Jakubowski, S. D.:
Effects of pressure on aqueous chemical equilibria at subzero temperatures with applications to Europa, Geochim. Cosmochim. Ac., 69, 259-274, 2005.

McDougall, T. J.: Potential enthalpy: a conservative oceanic variable for evaluating heat content and heat fluxes, J. Phys. Oceanogr., 33, 945-963, 2003.

McDougall, T. J., Jackett, D. R., and Millero, F. J.: An algorithm for estimating Absolute Salinity in the global ocean, Ocean Sci. Discuss., 6, 215-242, doi:10.5194/osd-6-215-2009, 2009.

Millero, F. J.: The physical chemistry of estuaries, in: Marine Chemistry in the Coastal Environment, edited by: Church, T. M., American Chemical Society, 25-55, USA, 1975.

Millero, F. J.: Effect of changes in the composition of seawater on the density-salinity relationship, Deep-Sea Res. Pt. I, 47, 15831590, 2000a.

Millero, F. J.: The Physical Chemistry of Natural Waters, WileyInterscience, New York, USA, 2000b.

Millero, F. J.: History of the equation of state of seawater, Oceanography, 23(3), 18-33, 2010.

Millero, F. J. and Lepple, F. K.: The density and expansibility of artificial seawater solutions from 0 to $40^{\circ} \mathrm{C}$ and 0 to $21 \%$ Chlorinity, Mar. Chem., 1, 9-104, 1973.

Millero, F. J. and Kremling, K.: The densities of Baltic Sea waters, Deep-Sea Res., 23, 1129-1138, 1976.

Millero, F. J. and Huang, F.: The density of seawater as a function of salinity ( 5 to $70 \mathrm{~g} \mathrm{~kg}^{-1}$ ) and temperature $(273.15$ to $363.15 \mathrm{~K})$, Ocean Sci., 5, 91-100, doi:10.5194/os-5-91-2009, 2009.

Millero, F. J., Gonzalez, A., Brewer, P. G., and Bradshaw, A.: The density of North Atlantic and North Pacific deep waters, Earth Planet. Sci. Lett., 32, 468-472, 1976a.

Millero, F. J., Gonzalez, A., and Ward, G. K.: The density of seawater solutions at one atmosphere as a function of temperature and salinity, J. Mar. Res., 34, 61-93, 1976b.

Millero, F. J., Forsht, D., Means, D., Giekes, J., and Kenyon, K.: The density of North Pacific Ocean waters, J. Geophys. Res., 83, 2359-2364, 1978.

Millero, F. J., Feistel, R., Wright, D. G., and McDougall, T. J.: The composition of Standard Seawater and the definition of the Reference-Composition Salinity Scale, Deep-Sea Res. Pt. I, 55, 50-72, 2008a.

Millero, F. J., Waters, J., Woosley, R., Huang, F., and Chanson, M.: The effect of composition on the density of Indian Ocean waters, Deep-Sea Res. Pt. I, 55, 460-470, 2008b.

Millero, F. J., Huang, F., Williams, N., Waters, J., and Woosley, R.: The effect of composition on the density of South Pacific Ocean waters, Mar. Chem., 114, 56-62, 2009.

Pawlowicz, R.: Calculating the conductivity of natural waters, Limnol. Oceanogr.-Meth., 6, 489-501, 2008.

Pawlowicz, R.: A model for predicting changes in the electrical conductivity, practical salinity, and absolute salinity of seawater due to variations in relative chemical composition, Ocean Sci., 6, 361-378, doi:10.5194/os-6-361-2010, 2010.

Pawlowicz, R., Wright, D. G., and Millero, F. J.: The effects of biogeochemical processes on oceanic conductivity/salinity/density relationships and the characterization of real seawater, Ocean Sci. Discuss., 7, 773-836, doi:10.5194/osd-7-773-2010, 2010.

Poisson, A. and Gadhoumi, M. H.: An extension of the Practical Salinity Scale 1978 and the equation of state 1980 to high salinities, Deep-Sea Res., 40, 1689-1698, 1993. 
Sarmiento, J. L. and Bryan, K.: An ocean transport model for the North Atlantic, J. Geophys. Res., 87(C1), 394-408, 1982.

Sarmiento, J. L. and Gruber, N.: Ocean Biogeochemical Dynamics, Princeton University Press, Princeton, 503 pp., 2006.

Seitz, S., Spitzer, P., and Brown, R. J. C.: Consistency of Practical Salinity measurements traceable to primary conductivity standards: Euromet project 918, Accredit. Qual. Assur., 13, 601-605, 2008.

Seitz, S., Spitzer, P., and Brown, R. J. C.: CCQM-P111 study on traceable determination of Practical Salinity and mass fraction of major seawater components, Accredit. Qual. Assur., 15, 9-17, 2010a.

Seitz, S., Feistel, R., Wright, D. G., Weinreben, S., Spitzer, P., and De Biévre, P.: Metrological traceability of oceanographic salinity measurement results, Ocean Sci. Discuss., 7, 1303-1346, doi:10.5194/osd-7-1303-2010, 2010 b.
UNESCO: Background papers and supporting data on the Practical Salinity Scale 1978, UNESCO Techn. Pap. Mar. Sci. 37, UNESCO, Paris, 144pp., 1981.

Wolf, H.: Determination of water density: limitations at the uncertainty level of $1 \times 10^{-6}$, Accredit. Qual. Assur., 13, 587-591, 2008.

Wong, A. P. S., Bindoff, N. L., and Church, J. L.: Large scale freshening of intermediate waters in the Pacific and Indian Oceans, Nature, 400, 440-443, 1999.

Wright, D. G., Feistel, R., Reissmann, J. H., Miyagawa, K., Jackett, D. R., Wagner, W., Overhoff, U., Guder, C., Feistel, A., and Marion, G. M.: Numerical implementation and oceanographic application of the thermodynamic potentials of liquid water, water vapour, ice, seawater and humid air - Part 2: The library routines, Ocean Sci., 6, 695-718, doi:10.5194/os-6-695-2010, 2010. 